\title{
Recording earthquakes for tomographic imaging of the mantle beneath the South Pacific by autonomous MERMAID floats
}

\author{
Joel D. Simon ${ }^{\circledR},{ }^{1}$ Frederik J. Simons ${ }^{\oplus 1}$ and Jessica C. E. Irving ${ }^{\circledR 2}$ \\ ${ }^{1}$ Department of Geosciences, Princeton University, Princeton, NJ 08544, USA. E-mail: jdsimon@alumni.princeton.edu \\ ${ }^{2}$ School of Earth Sciences, University of Bristol, Bristol BS8 1RJ, UK
}

Accepted 2021 July 14. Received 2021 July 9; in original form 2020 August 9

\begin{abstract}
SUMMAR Y
We present the first 16 months of data returned from a mobile array of 16 freely floating diving instruments, named MERMAID for Mobile Earthquake Recording in Marine Areas by Independent Divers, launched in French Polynesia in late 2018. Our 16 are a subset of the 50 MERMAID deployed over a number of cruises in this vast and understudied oceanic province as part of the collaborative South Pacific Plume Imaging and Modeling (SPPIM) project, under the aegis of the international EarthScope-Oceans consortium. Our objective is the hydroacoustic recording, from within the oceanic water column, of the seismic wavefield generated by earthquakes worldwide, and the nearly real-time transmission by satellite of these data, collected above and in the periphery of the South Pacific Superswell. This region, characterized by anomalously elevated oceanic crust and myriad seamounts, is believed to be the surface expression of deeply rooted mantle upwellings. Tomographically imaging Earth's mantle under the South Pacific with data from these novel instruments requires a careful examination of the earthquake-to-MERMAID traveltimes of the high-frequency $P$ wave detections within the windows selected for reporting by the discrimination algorithms on board. We discuss a workflow suitable for a fast-growing mobile sensor database to pick the relevant arrivals, match them to known earthquakes in global earthquake catalogues, calculate their traveltime residuals with respect to global seismic reference models, characterize their quality and estimate their uncertainty. We detail seismicity rates as recorded by MERMAID over 16 months, quantify the completeness of our catalogue and discuss magnitude-distance relations of detectability for our network. The projected lifespan of an individual MERMAID is $5 \mathrm{yr}$, allowing us to estimate the final size of the data set that will be available for future study. To prove their utility for seismic tomography we compare MERMAID data quality against 'traditional' land seismometers and their low-cost Raspberry Shake counterparts, using waveforms recovered from instrumented island stations in the geographic neighbourhood of our floats. Finally, we provide the first analyses of traveltime anomalies for the new ray paths sampling the mantle under the South Pacific.
\end{abstract}

Key words: Seismic instruments; Pacific Ocean; Body waves; Structure of the Earth; Seismic tomography.

\section{INTRODUCTION}

Seismic data recorded in the global oceans are sparse in both spatial and temporal coverage, especially in the Southern Hemisphere. Fig. 1 maps the location of every seismic station for which, in principle, data are retrievable from the Incorporated Research Institutions for Seismology (IRIS), showing how underserved the oceans are relative to the continents. The history of seismic studies in and under the oceans, which are complex and costly, is short, and no single seismic instrument has yet combined the ability to deliver high-quality data with autonomy, low cost, low latency and nimbleness. Our instrument named MERMAID for Mobile Earthquake Recording in Marine Areas by Independent Divers (Simons et al. 2009) fills a gap in instrumentation by providing low-cost seismoacoustic records suitable for global seismology (Simons et al. 2006b) from the oceans in near real-time (Hello et al. 2011) without the requirement of a research vessel for deployment and, being unrecovered, negating the need for a recovery cruise.

To place MERMAID in historical perspective: only about 100 seismic records from the deep-ocean bottom existed by the early 
(a)

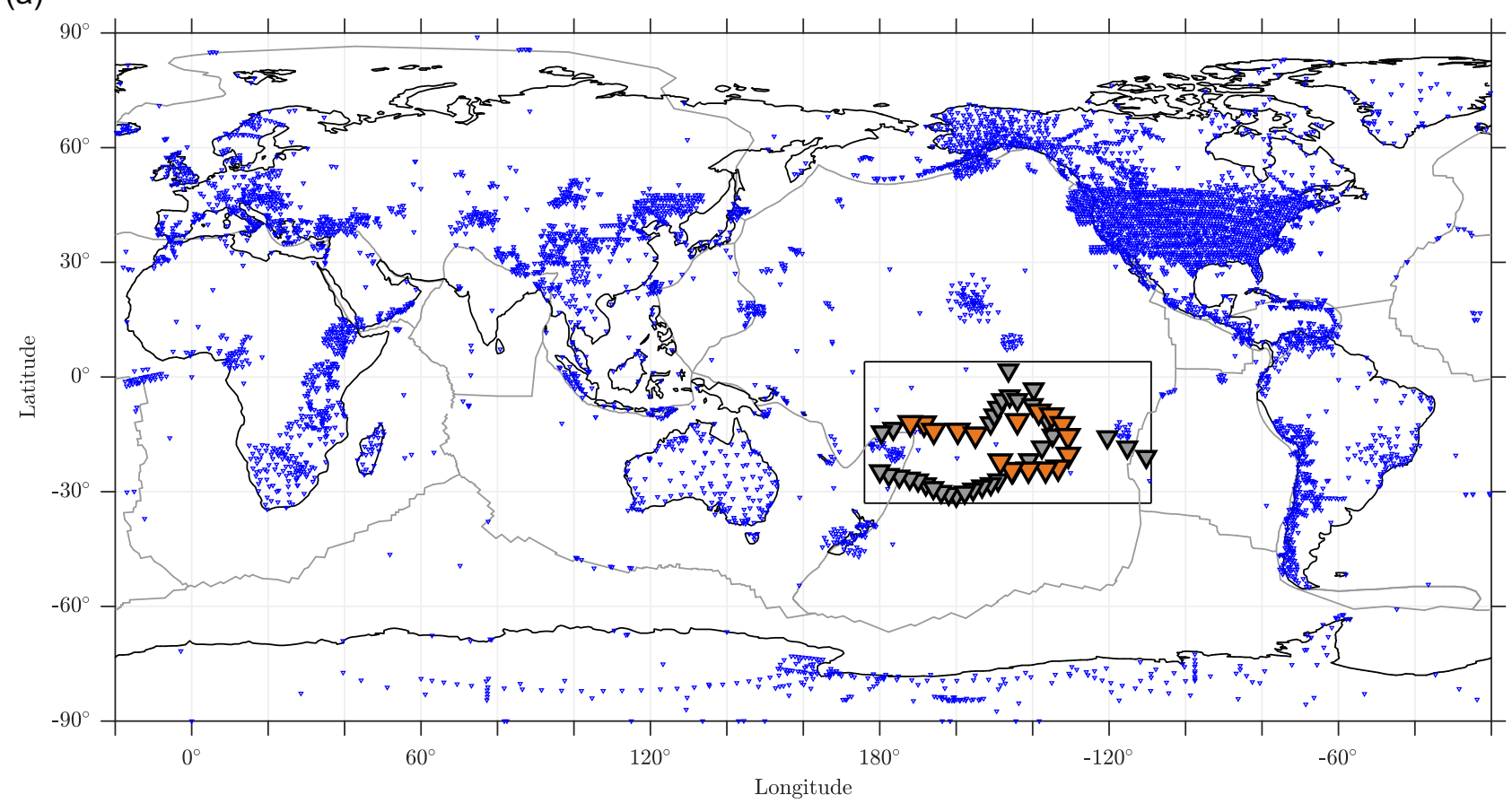

(b)

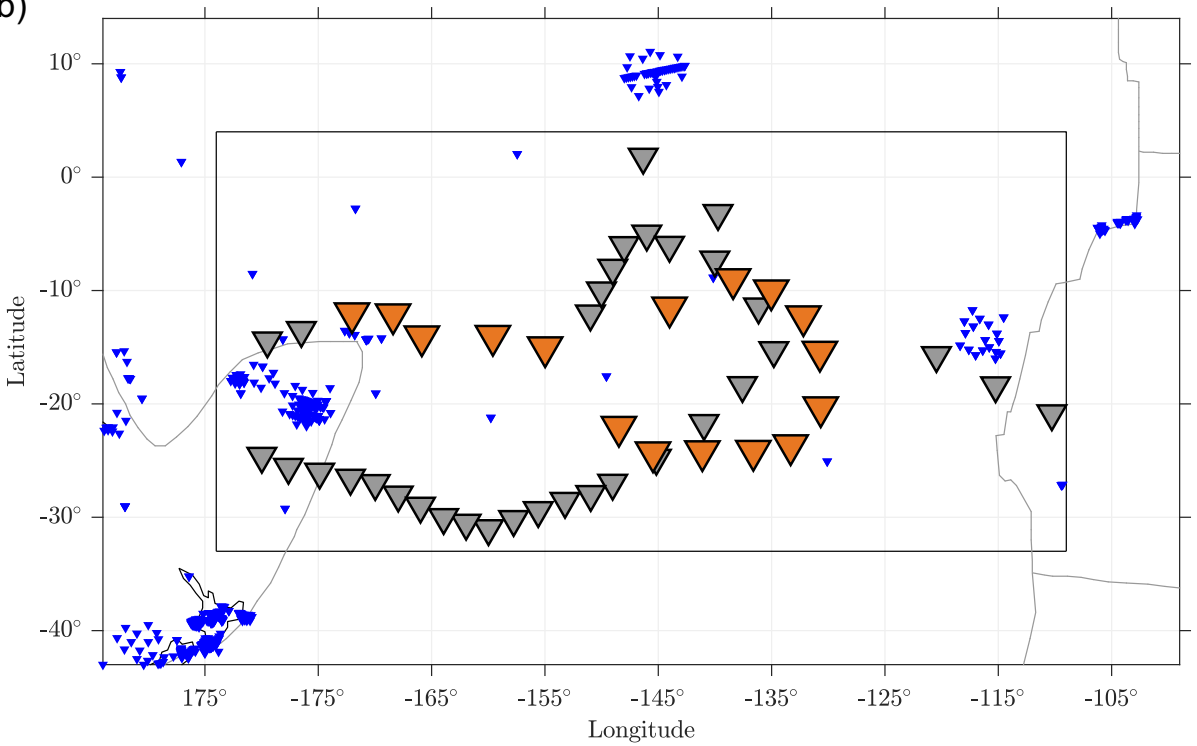

Figure 1. All 46295 seismic stations ever reported to the Incorporated Research Institutions for Seismology (IRIS), as of March 2020 (blue triangles), and the locations of MERMAIDs at the time of their deployment (orange and grey triangles). (a) Global map including plate boundaries. (b) Zoom in of the 50-MERMAID array with the 16 Princeton instruments in orange. The black rectangle inside both maps is the boundary of the region searched for nearby island stations.

1960s, according to Bradner (1964). Early attempts to instrument the oceans for regional and global seismology came in the form of seismometers dropped in free fall onto the seafloor from a ship, with a variety of mechanisms for recovery and data retrieval (Ewing \& Vine 1938; Bradner 1964; Whitmarsh 1970). Progress toward true instrument autonomy came in the form of freely drifting telemetered devices, either neutrally-buoyant mid-column floating versions of ocean-bottom sensors (Bradner et al. 1970), or sonobuoys, with a hydrophone loosely suspended from a surface buoy (Reid et al. 1973). Most of these experiments were short-lived due to power restrictions. Longer-lived moored sonobuoys (Kebe 1981) and hydrophones (Fox et al. 1993) provided continuous hydroacoustic data at the expense of requiring seafloor cables to power them, restricting their spatial coverage.

In the last three decades, ocean bottom seismometry with longlife robust, three-component broad-band sensors has flourished (Zhao et al. 1997; Webb 1998; Webb \& Crawford 2003; Suetsugu \& Shiobara 2014). Nevertheless, to this day such instruments remain physically large and expensive to install (Beauduin et al. 1996; Collins et al. 2001), requiring a specialized research vessel for deployment and recovery (Stephen et al. 2003). Establishing semi-permanent installations (Duennebier et al. 2002; 
Romanowicz et al. 2006) worldwide remains a developing goal for the international community (Montagner et al. 1998; Romanowicz \& Giardini 2001; Favali \& Beranzoli 2006; Kohler et al. 2020).

Evolving from single-station cabled seafloor installations (Butler et al. 2000; Petitt et al. 2002; Romanowicz et al. 2006), multistation, multi-instrument cabled arrays have been rooted on the seafloor offshore Japan (Hirata et al. 2002; Shinohara et al. 2014), the Canadian Northeast Pacific (Barnes et al. 2013; Matabos et al. 2016) and Oregon (Cowles et al. 2010; Toomey et al. 2014; Kelley et al. 2016). These installations provide high-quality data with low latency, but they require massive upfront costs, demand costly maintenance, are limited by cable access and, being permanent, cannot be rapidly reinstalled or reassigned in the case of developing seismic crises (e.g. Duennebier et al. 1997).

The current fleet of recovered ocean bottom seismometers (OBS) is autonomous but unable to transmit data while deployed, hence data acquisition and processing are separated by months or years, unless catastrophe precludes recovery (Tolstoy et al. 2006). More recently, wave-powered gliders that float at the surface and may be remotely controlled to remain in the vicinity of an ocean-bottom station have been used to relay data from seafloor to shore via acoustic modem and satellite uplink (Berger et al. 2016). This coupling of technologies allows the delivery of seismic data from the seafloor in near real-time. While they have shown promise, such solutions remain fragile and costly and they have not yet enjoyed large-scale deployment. Kohler et al. (2020) proposed a pilot experiment that would see the installation of a long-term broad-band seismic network on the seafloor utilizing the newest advances in wave glider and OBS technologies including in situ battery replacement. Such campaigns, where data are acquired autonomously and in near realtime and with instrument lifespans measured in years instead of weeks or months, will generate data sets complementary to those returned by MERMAID.

Beyond gliders, still other solutions to the logistical problem of data recovery are currently being tested, including ocean-bottom systems that periodically release data pods from the seafloor, each with a self-contained telecommunications unit to relay data via satellite upon surfacing (Hammond et al. 2019). Finally, while the age where the cables themselves may act as seismic sensors appears to have arrived (e.g. Lindsey et al. 2019; Sladen et al. 2019; Williams et al. 2019), such technology is in its infancy.

While MERMAID's data sets of hydroacoustic time-series, collected by a single hydrophone floating at mid-column water depths, forever will remain less 'complete' in comparison with data sets recorded by well-coupled three-component broad-band OBS, the benefits provided by the instrument are many. These include its lower manufacturing costs, its logistical simplicity, its algorithmic flexibility (Sukhovich et al. 2011, 2014) in selecting promising seismic phases to report with each surfacing, and its longevitycurrently projected to be about 5 yr ( $\sim 250$ dive cycles $)$ on a single lithium battery charge. Fulfilling the promise of the first-generation MERMAID instrument (Simons et al. 2009) and substantiating the record accumulated by MERMAIDs of the second generation (Sukhovich et al. 2015; Nolet et al. 2019; Simon et al. 2020), the nearly 1400 records presented here, collected by the current third generation of instruments, are closing the seismic data gap in the world's oceans.

Studying the interior of the Earth using seismic tomography (Nolet 2008; Romanowicz 2008; Rawlinson et al. 2010), primarily using $P$-delay times remains to date MERMAID's primary strength and objective. Joubert et al. (2016) and Nolet et al. (2019) have shown that the accuracy of MERMAID's position underwater, interpolated from multiple surfacings, and the accuracy with which the arrival time of seismic $P$ phases can be determined from the often noisy acoustic records, are of sufficiently high quality to constrain velocities for tomographic inversion. Simon et al. (2020) presented a new algorithm for the multiscale estimation of event arrival times and their precision, which closes the loop from detection and discrimination of $P$ waves in the ocean, to the accurate determination of their traveltimes, to the assessment of their uncertainties.

In this paper, we leverage all of these developments and present the first 16 months of data returned by the 16 MERMAIDs owned and operated by Princeton University that were deployed in French Polynesia in August and September 2018. We compare their waveforms with traces available from 20 seismic island stations in the same region, and with records from a set of five comparatively less expensive but increasingly more abundant Raspberry Shake instruments (Anthony et al. 2019).

We study the statistics and completeness of our growing catalogue of seismic data and estimate the total number of tomographicquality records that can be expected to be recorded by each MERMAID over its projected 5-yr lifetime. We compute MERMAID traveltime residuals against the 1-D ak135 velocity model of Kennett et al. (1995), correct those for bathymetry and MERMAID's cruising depth and, lastly, readjust them using the fully 3-D and elliptical $P$-wave speed model LLNL-G3Dv3 of Simmons et al. (2012). We compute signal-to-noise ratios (SNRs) and estimate the uncertainties on our residuals, and compare these statistics with a complementary data set derived from traditional seismometers and Raspberry Shake stations installed on nearby ocean islands. Traveltime residuals will be the input data for future tomographic inversions that use our uncertainties as weights.

Finally, for a taste of the likely signals from the Earth's mantle that will emerge from our data collection we project our carefully measured residuals onto their 1-D ray paths to reveal average velocity perturbations that tomographic studies will further investigate.

\section{THE MERMAID INSTRUMENT}

The purpose of the MERMAID float is to return seismic data of tomographic quality from the global oceans in near real-time. The instrument (Fig. 2) and its dive cycle (Fig. 3) were inspired by oceanic floats (Swallow 1955; Rossby \& Webb 1970; Davis et al. 1992, 2001), which have become ubiquitous in the global oceans (see Gould 2005, for historical perspective).

The international Argo program remains one such project of particular influence because it has been providing the scientific community with a wealth of temperature, salinity, and trajectory data over the last several decades (Lavender et al. 2000; Davis 2005; Roemmich et al. 2009; Abraham et al. 2013). Along with the payload required for in situ observations and hydrographic profiling, a contemporary Argo float is equipped with a hydraulic pump that modulates an expandable bladder and allows it to be neutrally buoyant at many mid-column depths, a Global Positioning System (GPS) for location tracking, and a satellite link for data transmission. A typical Argo dive cycle begins with the instrument sinking to a depth between 1000 and $2000 \mathrm{~m}$ below the sea surface, where it passively drifts for around $10 \mathrm{~d}$ before resurfacing. During ascent, its conductivitytemperature-depth (CTD) sensor measures a roughly vertical column of water. Once at the surface it acquires a GPS fix, transmits the new data via satellite, and the process repeats. Because they are autonomous and drift at the whim of ocean currents Argo floats are practically guaranteed to sample the water column at a previously 

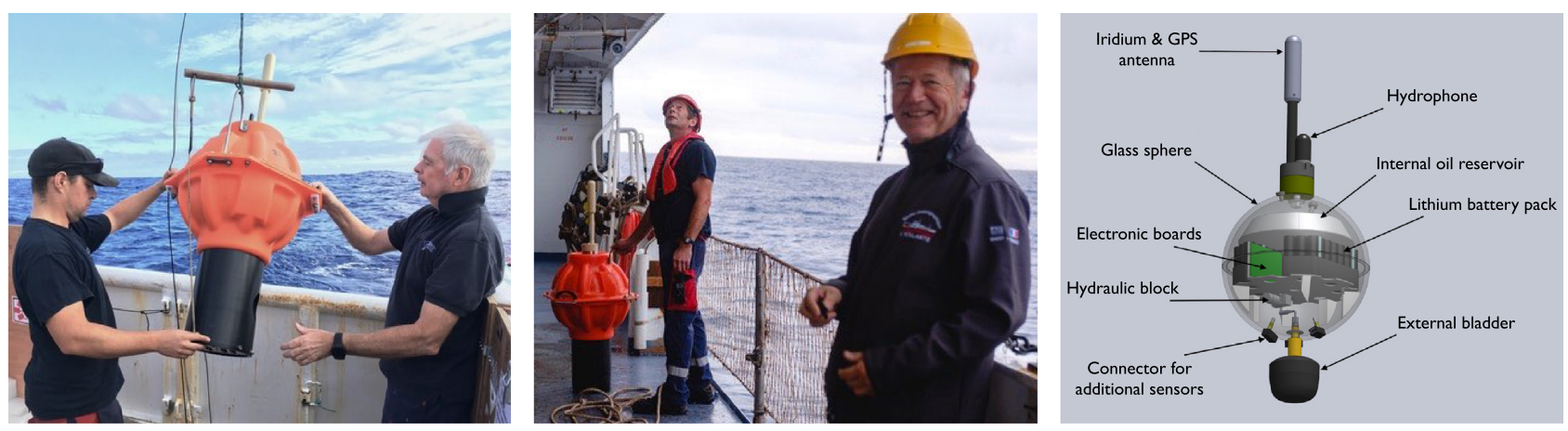

Figure 2. Third-generation MERMAID as deployed during the South Pacific Plume Imaging and Modeling (SPPIM) project. Left-hand panel: François Quemeneur and Jean-François 'Jeff' Barazer aboard R/V Alis, September 2018. Middle panel: Yann Hello aboard R/V L'Atalante in August 2019. In the background: Fernand Le Bousse. Photo by Lucas Sawade. Right-hand panel: technical drawing of the MERMAID instrument. Diagram provided by the manufacturer OSEAN SAS.

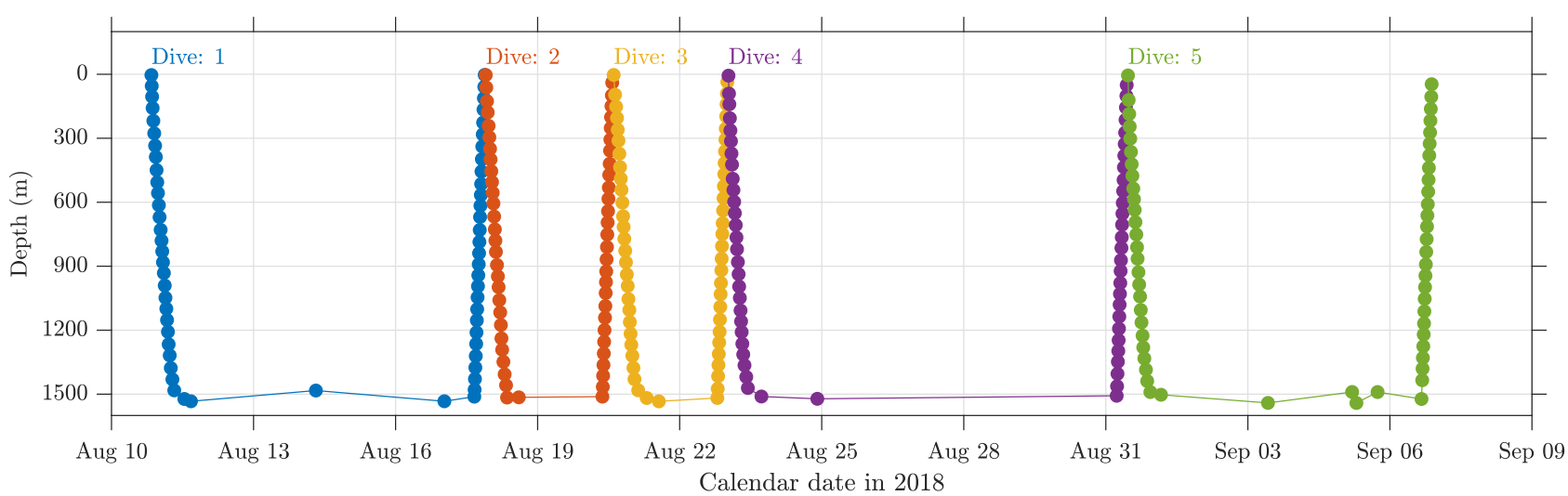

Figure 3. The first five dive cycles completed by MERMAID P0012. Filled circles mark individual pressure readings. Descent speeds are $-2.8 \pm 1.2 \mathrm{~cm} \mathrm{~s}^{-1}$ $\left(-100.3 \pm 44.8 \mathrm{~m} \mathrm{hr}^{-1}\right)$, for $15.5 \pm 5.3 \mathrm{hr}$ of sinking to $1500 \mathrm{~m}$. Ascent speeds are $8.0 \pm 0.2 \mathrm{~cm} \mathrm{~s}^{-1}\left(289.8 \pm 8.4 \mathrm{~m} \mathrm{hr}^{-1}\right)$, rising in $5.1 \pm 0.2 \mathrm{hr}$. MERMAID's algorithm prompts immediate surfacing upon recording a likely teleseismic $P$ wave, which explains the abbreviated durations of the second and third dives.

unsampled location every time they ascend. Some 4000 Argo floats are actively reporting from within every ocean on Earth, and on average some 800 are being deployed yearly to maintain the fleet. Like MERMAID, they are not designed to be recovered.

The first-generation MERMAID float was a SOLO (Sounding Oceanographic Lagrangian Observer) float (Davis et al. 2001) fitted with a hydrophone and a processing unit to return seismologically viable seismoacoustic data recorded at its parking depth (Simons et al. 2006b, 2009). The second-generation MERMAID (Hello et al. 2011; Sukhovich et al. 2015) was a modified APEX (Autonomous Profiling Explorer) float. The current third-generation MERMAID is a redesign from the ground up by Yann Hello at Géoazur and French engineering firm OSEAN SAS (Hello \& Nolet 2020). The autonomous float carries a High Tech HTI-96-Min Hex hydrophone, a Gardner Denver pneumatic pump, a u-blox NEO-M8N GPS unit, a two-way Iridium communication module, Electrochem lithium batteries, and dedicated onboard detection and discrimination software (Sukhovich et al. 2011). Once deployed MERMAID sinks to a predetermined depth (usually $1500 \mathrm{~m}$, adjustable) and records the ambient acoustic wavefield while freely drifting with the midcolumn currents. If triggered by seismic activity, or once a threshold time is reached, MERMAID surfaces, transmits the new data, downloads mission-command files via satellite, and repeats the process. Fig. 3 shows the first five dive cycles completed by MERMAID P0012 after its deployment on 10 August 2018, and Fig. 4(a) shows the drift trajectories of all 16 MERMAIDs discussed in this study.
The onboard algorithm used to monitor and process the ambient acoustic wavefield (Sukhovich et al. 2011, 2014) was designed to trigger on tomographic-quality teleseismic $P$-wave arrivals sensitive to mantle structure. Once parked at depth the hydrophone is switched on and data acquisition starts. The hydroacoustic data are processed in real-time by a short-term average over long-term average (STA/LTA) algorithm (Allen 1978), and written to a Secure Digital (SD) card, which retains them for $1 \mathrm{yr}$. If the adjustable STA/LTA threshold is exceeded, a windowed section of those data is further interrogated via wavelet decomposition ( $\mathrm{Si}$ mons et al. 2006a), and its energy distribution across six wavelet scales is compared with statistical models of various signals known to exist in the oceans (many of which are not generated by seismic events).

A quality criterion encodes the probability that the record under inspection includes a $P$-wave arrival. If the criterion is high, MERMAID immediately ceases data acquisition and surfaces to transmit the signal. Candidate signals that do not trigger immediate surfacing are stored in memory and marked for transmission at the next opportunity. For all records discussed in this study, MERMAID transmitted five of the possible six wavelet and scaling coefficient sets in the Cohen-Daubechies-Feauveau $(2,4)$ basis (Cohen et al. 1992) of a time-series originally sampled at $40 \mathrm{~Hz}$ and filtered between 0.1 and $10 \mathrm{~Hz}$ before digitization. The MERMAID records presented here are therefore seismoacoustic pressure time-series sampled at $20 \mathrm{~Hz}$. 

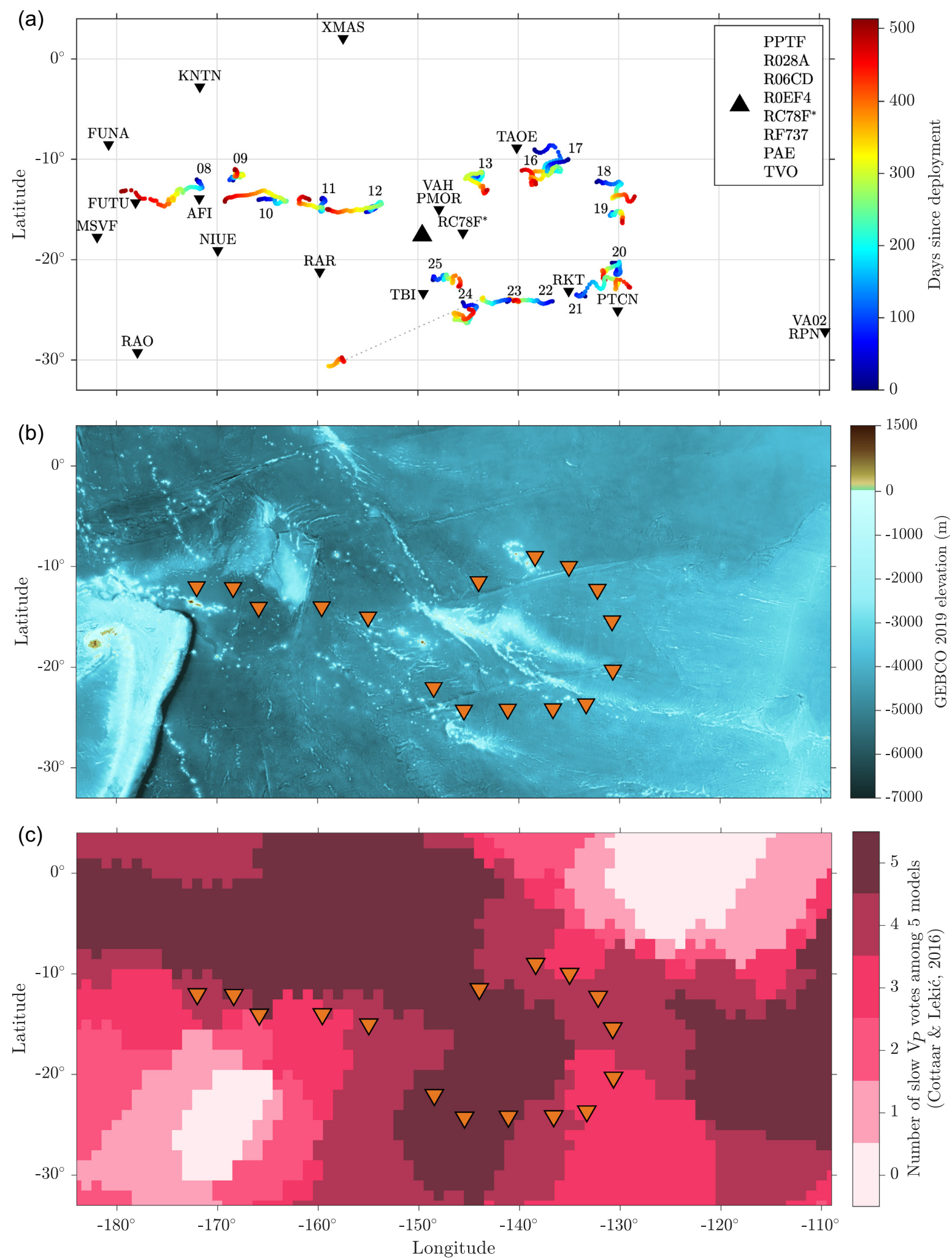

Figure 4. (a) MERMAID trajectories and the locations of (stationary) nearby island stations. This map is a zoom in of the rectangles drawn inside Figs 1(a) and (b), a bounding box framed roughly $2^{\circ}$ beyond the extent of the complete 50-MERMAID SPPIM array at the time of deployment and representing the total area searched for additional island seismic data. Only the drift trajectories of the 16 Princeton-operated MERMAIDs that contributed data to this study are shown. The trajectories are colour-coded by the time elapsed since deployment, approximately tracing ocean currents at the $1500 \mathrm{~m}$ parking depth. Locations of nearby island seismic installations are marked with triangles. Station RC78F appears twice, its name starred in the legend, because it was moved during this study period. (b) Deployment locations of the same 16 MERMAIDs (orange triangles) overlain on a map of bathymetry and topography from the 2019 model by General Bathymetric Chart of the Oceans (GEBCO Bathymetric Compilation Group 2019). (c) Deployment locations overlain on a map showing the number of votes among five models for anomalously slow $P$-wave velocities at $2700 \mathrm{~km}$ depth according to the clustering analysis of Cottaar \& Lekić (2016). 
MERMAID delivers seismic data from the oceans in near realtime with immediate surfacing and data transmission within hours of recording the strongest signals. MERMAIDs are individually programmable and mission parameters such as parking depth, maximum allowable time interval between GPS fixes, criterion thresholding values to trigger surfacing, and so on, all may be monitored and adjusted thanks to two-way Iridium communication. While the ability exists to request data from the buffer for up to $1 \mathrm{yr}$ prior (which we have done with success), we found the default trigger algorithm to perform well, and in this study we restrict our discussion to those triggered records that MERMAID sent us on its own accord. Indeed the default onboard algorithm was left untouched for the entirety of the deployment for all 16 floats discussed here.

\section{THE SOUTH PACIFIC PLUME IMAGING AND MODELING (SPPIM) PROJECT}

The 16 Princeton-operated third-generation MERMAIDs of this study are part of the SPPIM array of 50 MERMAIDs deployed into the South Pacific to study the underlying mantle composition and temperature using seismic tomography. Drifting united under the EarthScope-Oceans banner, these MERMAIDs are supported and maintained by a global consortium (http://earthscopeoceans.org). A profile of EarthScope-Oceans and a detailed deployment history of the SPPIM array are given in the Supporting Information.

\subsection{Geographic and geological context}

MERMAIDs drift with the ocean currents - they do not (yet) land on the seafloor like OBS. Fig. 4(a) shows the drift trajectories of the numbered floats discussed in this study. Every dot represents one GPS fix taken by MERMAID at the surface, colour-coded for time elapsed since its deployment (dark blue for the launch day, dark red for the last GPS fix of 2019). By connecting these dots we obtain an approximate (Davis 2005) map of the ocean currents at the $1500 \mathrm{~m}$ parking depth. See Nolet et al. (2019) for drift statistics broken down into shallow- and deep-drift components. Also labeled in Fig. 4(a) are the locations of other seismic sensors against which MERMAID data are compared later in this study. Those are individually marked by triangles, except for the collection of stations on Tahiti, French Polynesia, which is marked by a single larger triangle with the corresponding station codes listed in the legend.

For added geological and geodynamic context Fig. 4(b) shows a bathymetric map of the same region. We see myriad islands, seamounts (Wessel et al. 2010), hotspot tracks (Wessel \& Kroenke 1997), and, in lighter colours, large swaths of anomalously elevated oceanic crust known as the South Pacific Superswell (McNutt \& Fischer 1987; McNutt \& Judge 1990).

Fig. 4(c) is a 'vote' map according to the clustering analysis of Cottaar \& Lekić (2016), marking the number of models showing anomalously slow $P$-wave velocities at $2700 \mathrm{~km}$ depth. The five models in use are HMSL-P06 (Houser et al. 2008), GyPSuM (Simmons et al. 2010), LLNL-G3Dv3 (Simmons et al. 2012), SPani (Tesoniero et al. 2015) and ME2016 (Moulik \& Ekström 2016), selecting $V_{P}$ where both $V_{P}$ and $V_{S}$ were available. Cottaar $\&$ Lekić (2016) classified $P$-wave velocities at discrete locations within those five models into three bins: slow, neutral and fast. Three models concurring are a 'majority', and five a 'consensus'.
In Fig. 4(c) we see a consensus among all models that large regions exhibiting anomalously slow $P$-wave velocities lie at the base of the mantle under the South Pacific (Tanaka et al. 2009a). This region is known as the Pacific Large Low-Velocity Province (LLVP) and is one of two nearly antipodal regions on Earth, the other being the African LLVP (Garnero et al. 2016). Combined, Fig. 4 shows the SPPIM array from the water column to the core-mantle boundary $(\mathrm{CMB})$ to frame the features above which it drifts. However, the majority of seismoacoustic data that our SPPIM array records traverses mantle features between these two extremes, and the webbased SubMachine tool (Hosseini et al. 2018) can be used to redraw this vote map (Shephard et al. 2017) with various models at different depths.

The exact nature of the interaction between LLVPs and surface features like oceanic hotpots and the South Pacific Superswell has long been a topic of debate (e.g. Davaille 1999; Adam et al. 2014). Compelling evidence in the form of whole-mantle tomography (French \& Romanowicz 2015) implies that the former may feed the latter via conduits of hot uprising rock that span, potentially discontinuously, from the CMB to the surface. The exact geometries, dimensions, and rooting structures of these conduits within or near the boundaries (Cottaar \& Romanowicz 2012) of LLVPs remain an area of active research (Garnero et al. 2016). What is known for certain is that the Pacific LLVP is expansive in breadth and height, purportedly rising to the mantle transition zone under the South Pacific Superswell (e.g. Tanaka et al. 2009b; Cottaar \& Lekic 2016), it is characterized by anomalously slow seismic velocities, and it lies under our SPPIM deployment. The teleseismic arrivals recorded by MERMAID are therefore expected to sample slow regions of the deep mantle, and their measurement will help refine future tomographic studies.

\subsection{Filling the data gaps}

Fig. 5 shows record sections that include data recorded by MERMAID and nearby island stations corresponding to four earthquakes, one each within the magnitude ranges: (a) M 5-5.9; (b) M 66.9 ; (c) $M$ 7-7.9; and (d) $M$ 8-8.9.

The colourful traces are MERMAID pressure records in the uncorrected units of digital counts. In the range of frequencies $(1-5 \mathrm{~Hz})$ that we discuss in this study the response is known to be flat (Guust Nolet, Olivier Gerbaud, and Frédéric Rocca, personal communication, 2021; see the Supporting Information and the Appendix ). Each MERMAID seismogram is arbitrarily colour-coded so that it is easily distinguishable. The precise length of each seismogram varies based on the triggering parameters of the STA/LTA algorithm. With current defaults they are generally between 200 and $300 \mathrm{~s}$ long. The seismograms in Fig. 5 are demeaned, detrended, and tapered with a 0.1-ratio cosine-taper (Tukey) window, and band-passed between 1 and $5 \mathrm{~Hz}$ using a one-pass, four-pole Butterworth filter. Each trace is normalized for plotting, resulting in arbitrary amplitudes within and between the panels of Figs 5(a)-(d). The black and grey curves correspond to the theoretical traveltimes of the phase(s) quoted in the legend as computed in the ak135 velocity model (Kennett et al. $1995)$ for the event identified in the title. Seismoacoustic phases beyond the $P$ wave, for example the $S$-wave arrival evident near the end of the MERMAID P0009 trace in Fig. 5(a; in yellow), are examined by Simon et al. (2021b).

The grey traces in Fig. 5 are velocity seismograms from nearby stations, again normalized per trace for easy viewing. Station names are labeled inside the right ordinate axis. Overlapping traces were 
(a)

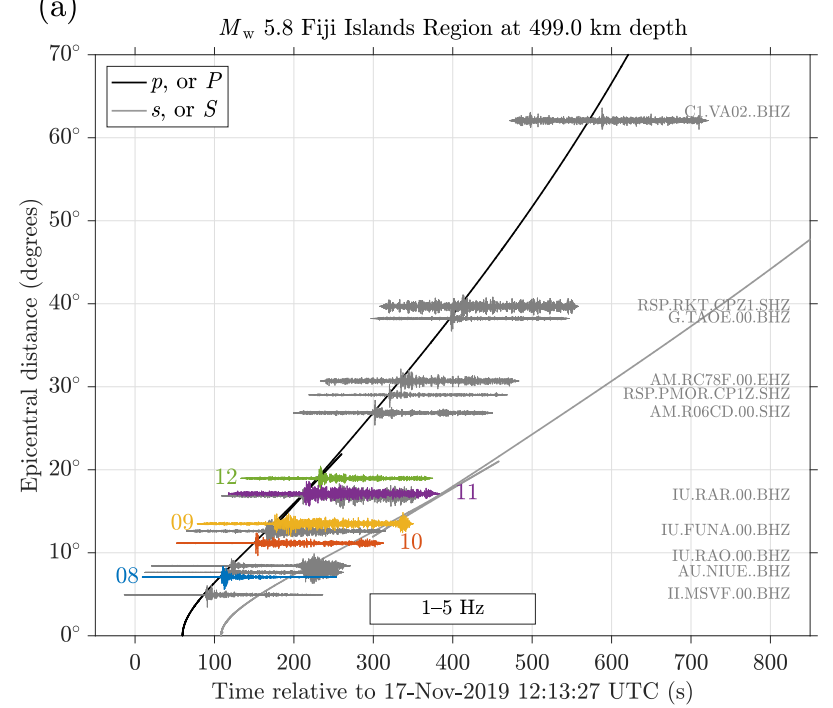

(c)

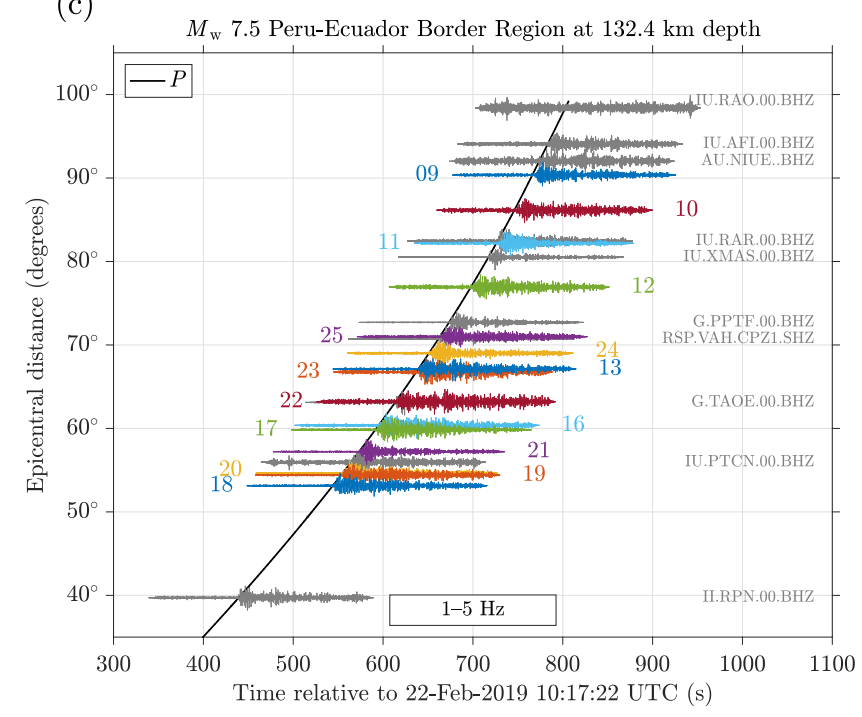

(b)

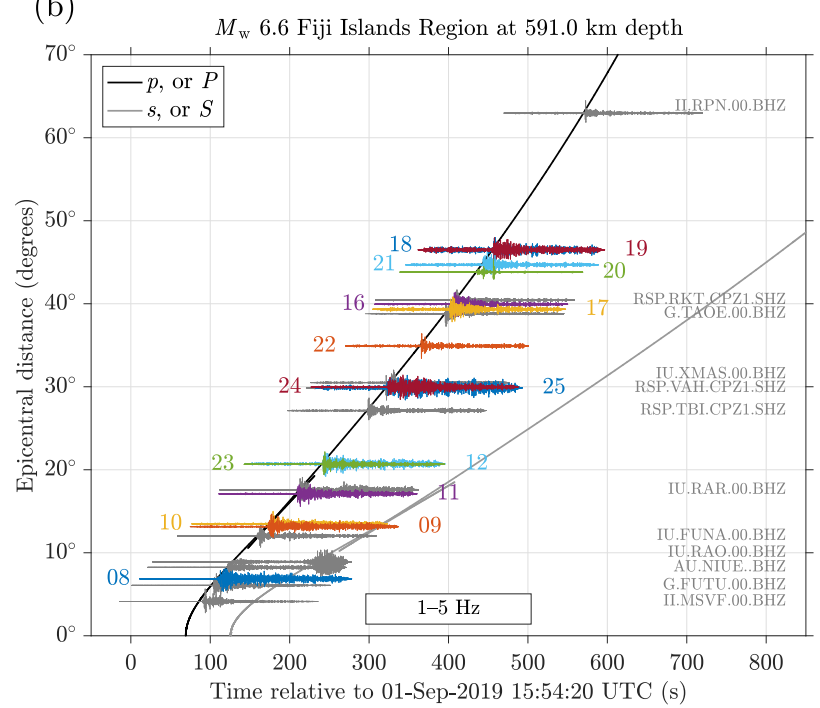

(d)

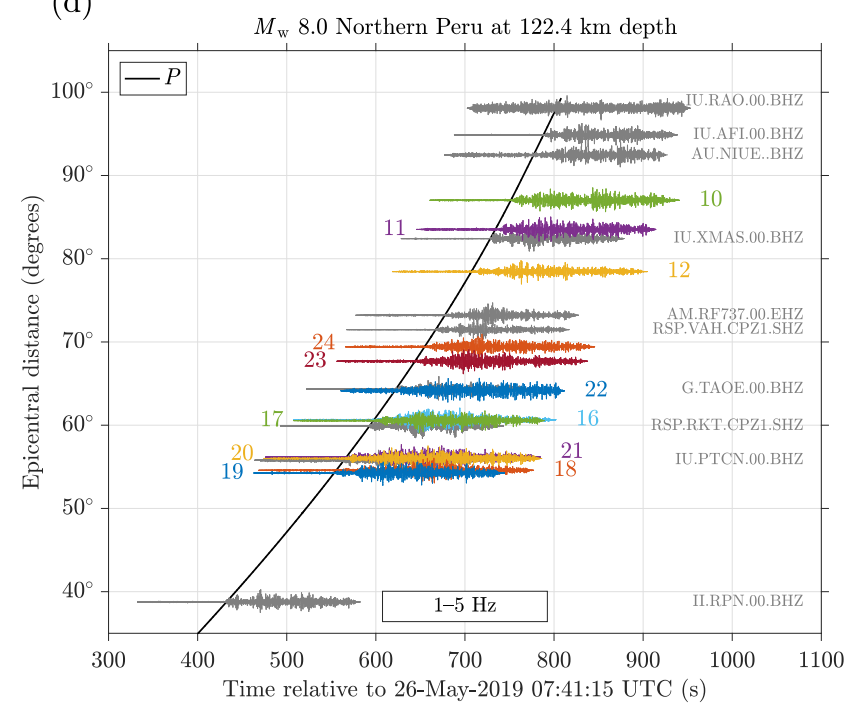

Figure 5. Record sections for different earthquakes. Coloured traces are MERMAID pressure records and grey traces are velocity seismograms from nearby island stations (traditional and Raspberry Shake). All traces are filtered between 1 and $5 \mathrm{~Hz}$. Two-digit serial numbers preceding or following each colourful trace identify the recording MERMAID, and island station names are in grey. Theoretical traveltime curves computed in the ak135 velocity model (Kennett et al. 1995), corresponding to the events quoted in the titles, are overlain as black and grey curves and identified in the legends.

removed. To mimic the MERMAID records we trimmed all seismograms to $250 \mathrm{~s}$, with the theoretical first-arrival time at $100 \mathrm{~s}$ (the approximate time of the STA/LTA trigger in MERMAID seismograms). We see that MERMAID SNRs for the events shown compare favourably to those of the island stations. This comparison is formalized in Section 5.2 for high-quality residuals culled from all three instrument platforms.

The MERMAID algorithm identifies time-series determined via probabilistic wavelet-subspace analysis to be likely teleseismic $P$ wave arrivals. The algorithm does not provide arrival-time picks beyond the precision afforded by the underlying STA/LTA detection algorithm, nor is it privy to recent global seismicity. Therefore, to produce record sections like those in Fig. 5 we must first determine if the seismograms match any events in a global catalogue. We searched the National Earthquake Information Center Preliminary Determination of Epicenters (NEIC PDE) Bulletin (https://earthquake.usgs.gov/data/comcat/catalog/us/) for recent events. The Supporting Information details the matching procedure by which we associate MERMAID seismograms with their corresponding earthquakes. We label positively matched seismograms as 'identified.'

\section{THE MERMAID EARTHQUAKES CATA L O GUE}

We will first take a broad look at the seismic catalogue itself, before drilling down to the statistics of the rate of return of identified events for individual MERMAIDs. We will also discuss the completeness of our catalogue as compared to other global seismic catalogues available over our study period. The purpose of this section is to answer questions relevant to any new seismic instrument, such as: "How many earthquakes does MERMAID record per year, and what are the distributions of their magnitudes, epicentral distances and locations?"; "What do the recorded magnitude-distance relations tell us about detectability thresholds?"; and "What is the probability that any single earthquake will be recorded by any single 
(a)

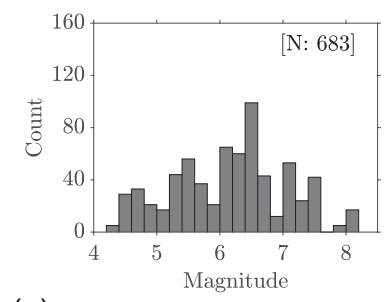

(b)

(c)
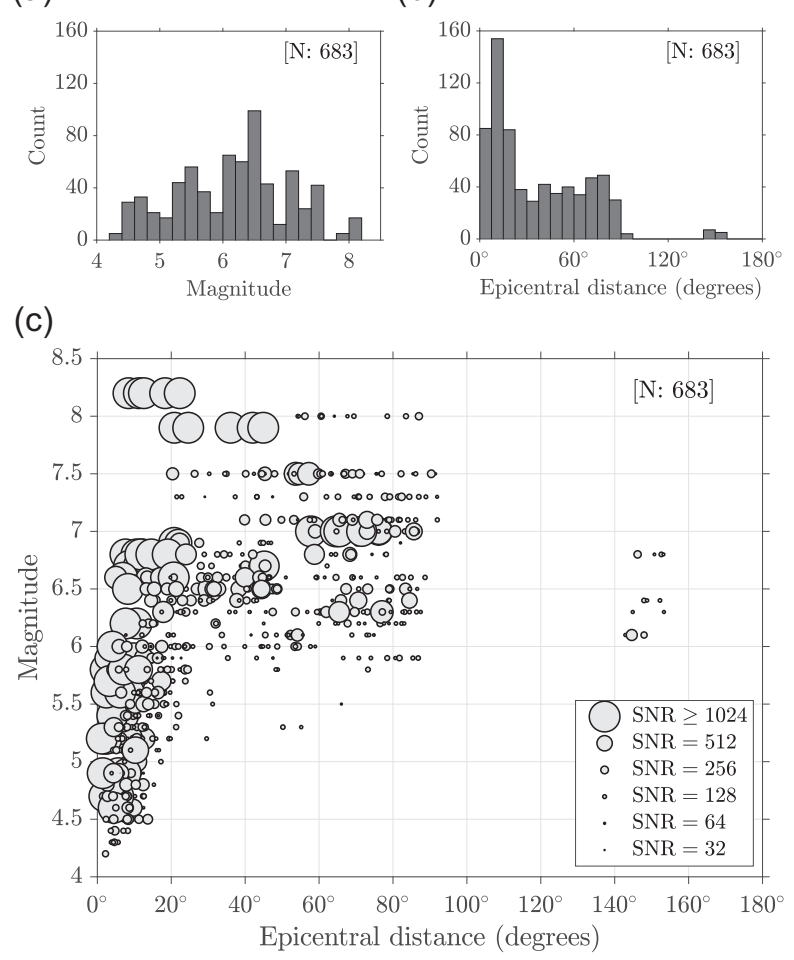

Figure 6. Earthquake magnitudes, epicentral distances, and signal-to-noise ratios (SNRs) in our data set. (a) Histogram of earthquake magnitudes. (b) Distribution of earthquake epicentral distances is roughly uniform out to around $90^{\circ}$, except for the peak around $10^{\circ}$, which arises from frequent M 4-4.9 earthquakes near Fiji sampled by the most proximal floats, mainly P0008. (c) Scatter plot with marker sizes representing the SNRs of individual arrivals. A lower-detection threshold hovers just above $M 6$ near $160^{\circ}$, where MERMAID picks up core phases. The horizontal strings of points are due to the fact that often more than one MERMAID reports the same earthquake.

MERMAID, and how many earthquakes is each projected to record in its lifetime?"

\subsection{Earthquake catalogue summary: in pictures}

Fig. 6 plots the distributions of earthquake magnitudes, distances and SNRs in the first earthquake-detectability diagram for the thirdgeneration MERMAID. The SNR is the estimated variance ratio of the signal and noise segments,

$\mathrm{SNR}=\hat{\sigma}_{\text {signal }}^{2} / \hat{\sigma}_{\text {noise }}^{2}$,

as identified by our picking procedure (see the Appendix), applied to a $30 \mathrm{~s}$ window filtered between 1 and $5 \mathrm{~Hz}$ and centred on the theoretical first arrival. Fig. 7 plots the ray paths for those earthquakes, binned by event depth. In all, 683 MERMAID seismograms were identified as containing at least one phase arrival associated with one of 288 unique earthquakes.

Fig. 6(a) shows that MERMAID sampled a fairly large range of earthquake magnitudes. The smallest earthquake, a $m_{\mathrm{b}} 4.2$ at $97.8 \mathrm{~km}$ depth in Tonga Islands, was recorded by P0008 at an epicentral distance of $2.2^{\circ}$. The largest event, a $M_{\mathrm{w}} 8.2$ on 19 August 2018 at $600.0 \mathrm{~km}$ depth in the Fiji Islands Region, was recorded by all five MERMAIDs deployed at that time (see Table 1 for SPPIMarray deployment dates). The mean magnitude of all events recorded is $M$ 6.2. The numbers of MERMAIDs reporting earthquakes, broken down by magnitude, are discussed in Section 4.2. Fig. 6(b) is
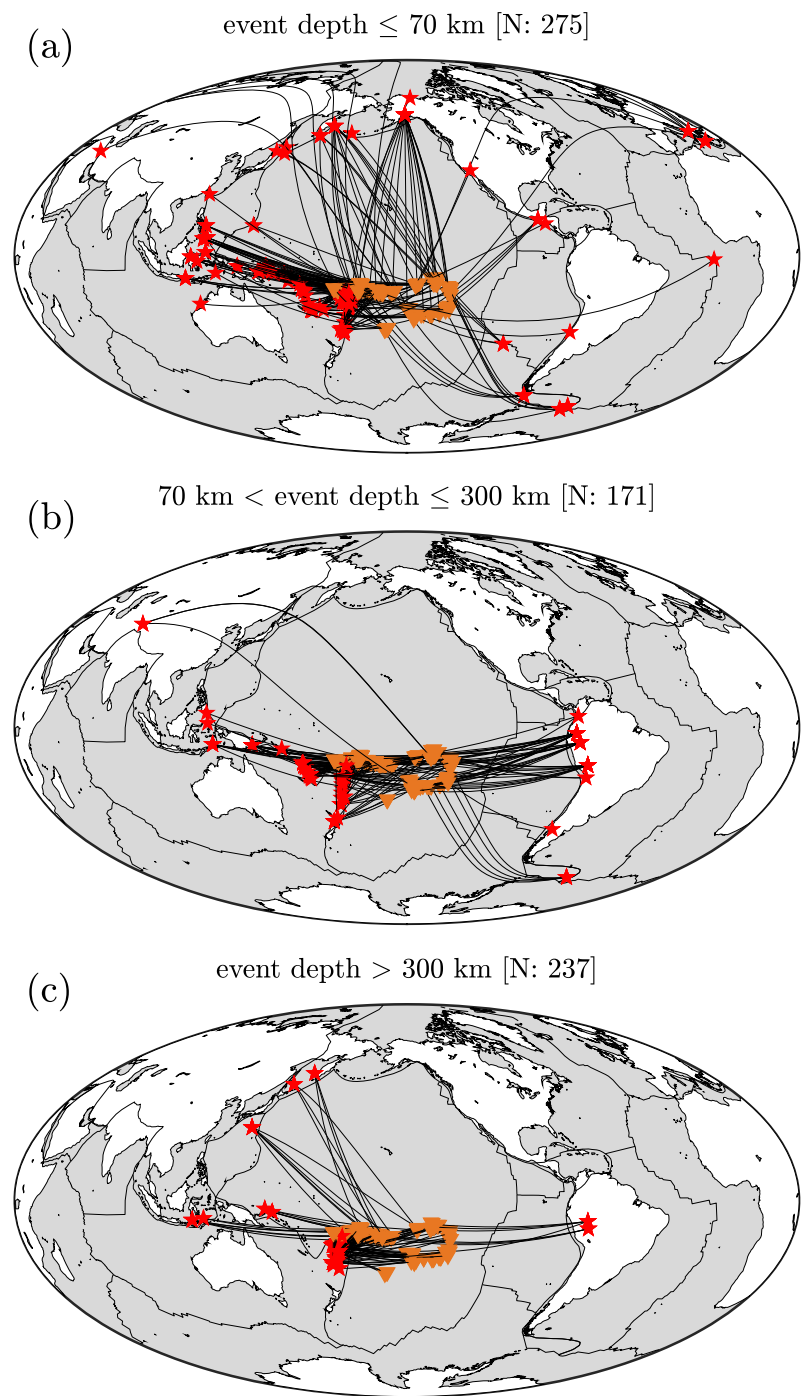

Figure 7. Source-receiver ray paths in our data set, separated by event depth (shallow, intermediate, and deep). Great-circle paths (black curves) connect the earthquake epicentres (red asterisks) with interpolated locations of MERMAIDS at the time of recording (orange triangles).

a histogram of those same earthquakes but now binned in terms of their epicentral distances. We see fairly consistent sampling at a variety of epicentral distances, implying MERMAID samples tomographically useful data at the global scale, including phases which have transited the core of the Earth (Simon et al. 2021b). Finally, Fig. 6(c) plots the SNRs of the first-arriving phases, represented by the size of the marker, as a function of magnitude and epicentral distance.

These are the first global detectability statistics for the thirdgeneration MERMAID - to be compared to the first-generation results shown by Simons et al. (2009). We see trends common to all seismic instruments: small events are preferentially recorded at short epicentral distances before geometrical spreading and attenuation sap them of their energy, while larger events (greater than $M 6$ in the case of MERMAID) may be recorded globally.

Fig. 7 places the data of Fig. 6 into their geographical context. The ray paths between earthquake epicentres and MERMAID locations at the time of recording are binned by event depth: shallow-focus (Fig. 7a, at less than $70 \mathrm{~km}$ ); intermediate-focus (Fig. 7b, between 70 and $300 \mathrm{~km}$ ); and deep-focus (Fig. 7c, greater than $300 \mathrm{~km}$ ). 
Table 1. The earthquake catalogue of the 16 Princeton MERMAIDs, complete to end of 2019. Some values in Tables 16 are rounded only after performing the relevant operations on the unrounded data, explaining the apparent inconsistency between some multiples, sums and means.

\begin{tabular}{lccccccc}
\hline MERMAID & Deployment & \# Wks. & \# Seis. & \# ID & per cent ID & $\frac{\text { \# Seis. }}{\text { yr }}$ & $\frac{\text { \# ID }}{\text { yr }}$ \\
\hline P0008: & 05-Aug-2018 & 73.3 & 256 & 188 & 73.4 & 182 & 134 \\
P0009: & 06-Aug-2018 & 73.2 & 131 & 95 & 72.5 & 93 & 68 \\
P0010: & 07-Aug-2018 & 73.1 & 125 & 85 & 68.0 & 89 & 61 \\
P0011: & 09-Aug-2018 & 72.8 & 76 & 53 & 69.7 & 54 & 38 \\
P0012: & 10-Aug-2018 & 72.6 & 247 & 45 & 18.2 & 178 & 32 \\
P0013: & 31-Aug-2018 & 69.6 & 216 & 29 & 13.4 & 162 & 22 \\
P0016: & 03-Sep-2018 & 69.2 & 48 & 26 & 54.2 & 36 & 20 \\
P0017: & 04-Sep-2018 & 69.1 & 34 & 23 & 67.6 & 26 & 17 \\
P0018: & 05-Sep-2018 & 68.9 & 23 & 20 & 87.0 & 17 & 15 \\
P0019: & 06-Sep-2018 & 68.7 & 20 & 19 & 95.0 & 15 & 14 \\
P0020: & 08-Sep-2018 & 68.5 & 89 & 13 & 14.6 & 68 & 10 \\
P0021: & 09-Sep-2018 & 68.3 & 15 & 15 & 100.0 & 11 & 11 \\
P0022: & 10-Sep-2018 & 68.2 & 12 & 12 & 100.0 & 9 & 9 \\
P0023: & 13-Sep-2018 & 67.8 & 33 & 26 & 78.8 & 25 & 20 \\
P0024: & 13-Sep-2018 & 67.8 & 19 & 19 & 100.0 & 15 & 15 \\
P0025: & 14-Sep-2018 & 67.6 & 19 & 15 & 78.9 & 15 & 12 \\
\hline Total: & & 1118.9 & 1363 & 683 & & 43 & 996 \\
Mean: & 29-Aug-2018 & 69.9 & 85 & 43 & 497 \\
\hline
\end{tabular}

Listed above each map in Fig. 7 is the number of seismograms recording events within those depth ranges. We find that MERMAID records shallow events most often, with 275 corresponding seismograms reported by our 16 MERMAIDs, although the counts for the other depths prove that MERMAID records earthquakes originating at depths from the shallow crust to deep within subducting slabs. The shallowest earthquake in the catalogue had its hypocentre at $2.2 \mathrm{~km}$ under Northern Alaska, and the deepest ruptured at a depth of $652.4 \mathrm{~km}$ below the Fiji Islands Region. Fig. 7 also shows that MERMAID primarily recorded subductionzone earthquakes occurring along the Pacific Rim, the 'Ring of Fire' of nearly continuous chains of volcanoes fed by subducting oceanic crust that encircles the Pacific Ocean from New Zealand to Chile (Rinard Hinga 2015). Approximately 90 per cent of annual global seismicity occurs in this most active of regions.

Figs 6 and 7 combine data for all 16 floats in the Princetonoperated fleet. These numbers mask the variability in the rate of seismicity recorded by individual floats. In what follows we parse the catalogue by float to capture the idiosyncrasies of each.

\subsection{Earthquake catalogue summary: by the numbers}

Table 1 is a breakdown of the rate of return of seismograms per MERMAID. The first column lists the MERMAID serial numbers, the second their deployment dates, and the third the total duration in weeks over which each MERMAID was active from deployment to the end of 2019. The fourth and fifth columns list the total number of seismograms returned, and the subset of those identified, respectively, and the sixth column quotes the latter as a percentage. The seventh column lists the average number of seismograms returned per full year of activity, and the eighth column lists the same statistic pertaining to the identified seismograms only. The penultimate row totals the columns, while the ultimate row lists their averages. Some values in Table 1 are rounded to the nearest integer, potentially only after performing the requisite operation implied by the row or column. As such, some values that are reportedly multiples, sums or means of other table entries may not be entirely self-consistent.
Let us first take a bird's-eye view of the data presented in Table 1 before teasing apart the statistics of the rate of return of individual MERMAIDs. From the penultimate row of Table 1 we see that our 16 MERMAIDs enjoyed a cumulative total of 1118.9 weeks (21.4 yr) of deployment in the South Pacific, over which time they recorded and transmitted 1363 seismograms. Of those, 683, around half of the set, were positively associated with events in global catalogues available at the time using the methodology described in the Supporting Information (Fig. S1). By summing yearly return rates, we find that our subset of the SPPIM array achieved a cumulative rate of return of 996 seismograms per year of deployment. Given the historical identification rate from column six this equates to about 497 identifications per year. The other seismograms represent myriad diverse signals corresponding to small or local events, oceanic $T$ waves from unidentified sources, as well as a substantial number of what we suspect to be instrument glitches, which almost exclusively affected MERMAIDs P0012, P0013 and P0020. To be clear, the MERMAID catalogue contains many seismograms which are unidentified by the standards upheld here, but which do in fact record earthquakes that otherwise went undetected by the global seismic network - not every unidentified event is just noise.

These data are further distilled in the last row of Table 1 where we list the rate of the return of an 'average' MERMAID. There we quote the means of the columns, that is, not weighted by the length of time that any individual MERMAID was deployed. Ergo, the final value in this row is the number of identified seismograms expected from any MERMAID in any given year. Our sample size of 16 is small and limited in time and space, but this number is the first step towards defining the expected long-term output of an 'average' MERMAID. The final value in this row is perhaps most relevant for future MERMAID deployments: on average each instrument returned 31 identified seismograms per year. With a projected lifespan of $5 \mathrm{yr}$, we expect a return of over 150 positively identified seismograms over the lifetime of each MERMAID.

The values in the final column which contribute to this mean are broadly distributed, ranging from a maximum of 134 returned by P0008, to a minimum of 9 returned by P0022. This spread 
(a)

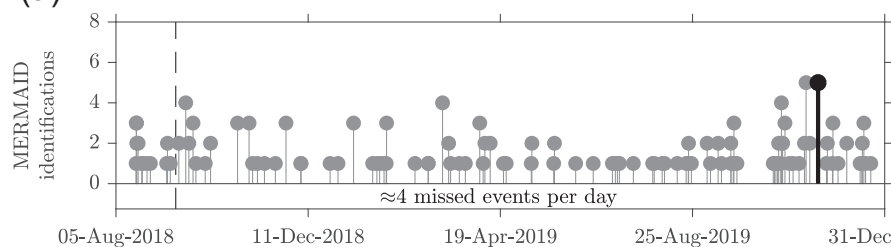

(c)

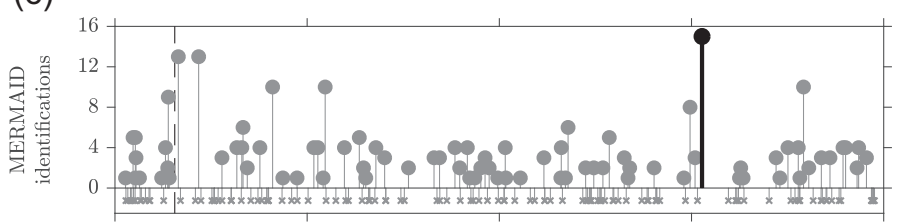

11-Dec-2018

19-Apr-2019

31-Dec-2019

(b)

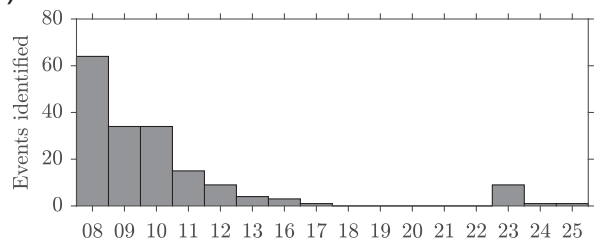

(d)

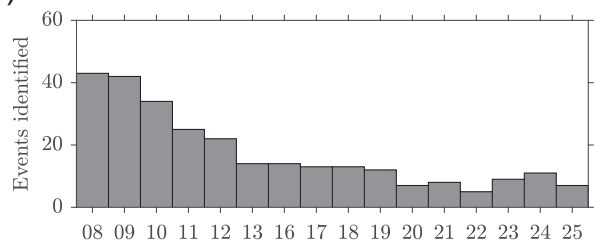

(f)

(e)
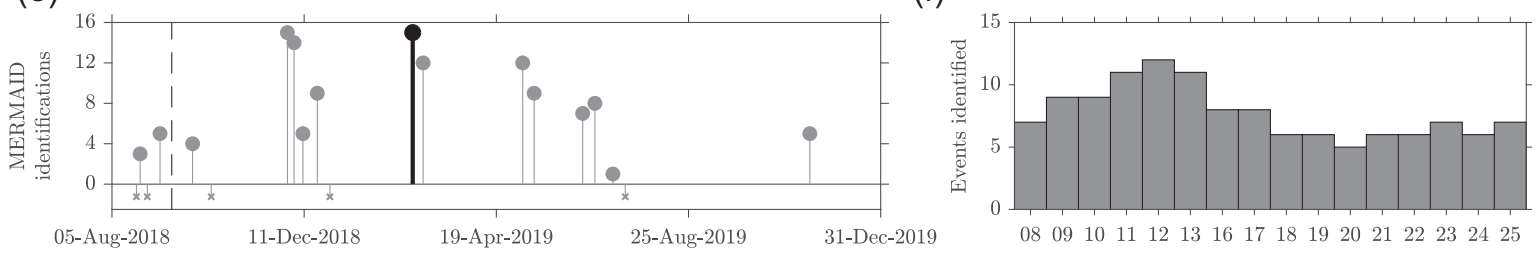

(h)

(g)

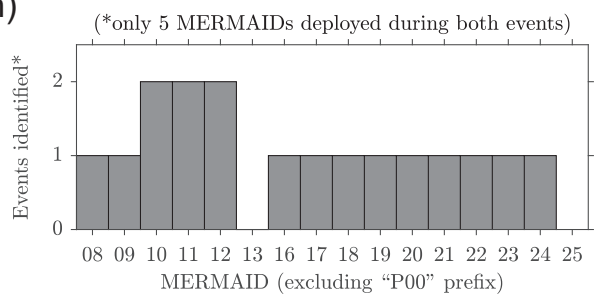

Figure 8. Earthquakes identified in MERMAID records between 5 August 2018 (P0008 deployment) and 31 December 2019, by magnitude. The stem plots of the left-hand column show the number of MERMAIDs positively identifying an event known to the NEIC PDE Bulletin, with missed events (0 MERMAIDs reporting) marked as crosses below the zero line, excepting in panel (a), which tallied so many misses that its average is simply reported there to avoid visual clutter. In each, the event in bold corresponds to the earthquake that resulted in the most MERMAID identifications for that magnitude range, shown in Figs 5(a)-(d), respectively. The dashed vertical line marks the completion of the 16-MERMAID Princeton fleet on 14 September 2018. The histograms of the right-hand column parse the total number of events identified by each float. Note that they do not necessarily imply a per-MERMAID identification rate because they remain unadjusted for deployment duration (e.g. MERMAIDs numbered P0013 and above were not yet deployed during the first M8 event in the final row, which explains why those instruments count at most a single identification).

is not due to implicit differences in the floats - indeed they all are identical both in manufacturing and software, and the programmable parameters (e.g. parking depth, detection criteria thresholds, etc.) were left unchanged for the duration of the deployments. Rather, this variance is most likely due to the geographic distribution of MERMAIDs. Instrument P0008, the busiest of the group, returned so many identifiable seismograms because it cruised the oceanic region between Fiji and Samoa, near enough to the former (and drifting closer-see Fig. 4) to record many seismograms matched to light and moderate earthquakes whose energy never registered on the more distant MERMAIDs in the open ocean.

Apart from simple source-receiver distance considerations, other variables influencing the rates of return are the local oceanic and bathymetric environments. We hypothesize that most notable among these are ocean storms. Mid-column noise has been shown to correlate strongly with wind speed (McCreery \& Duennebier 1993; Nichols \& Bradley 2016). Additionally, the SNRs of signals received by MERMAID are mediated by factors that do not impact common terrestrial stations. As is the case for any ordinary terrestrial station the noise is time variable, but perhaps more importantly the impedance along the ray path between a repeating earthquake and MERMAID is also time variable, in contrast to terrestrial stations that do not drift. A drifting MERMAID may find itself in regions with varying sedimentary cover, attenuating or amplifying incident $P$-wave energy, resulting in weaker or stronger acoustic conversion at the seafloor (Ewing et al. 1957; Stephen 1988). Multiple additional factors such as local water depth (Lewis \& Dorman 1998; Weatherall et al. 2015), the presence of nearby seamounts and other kinds of rough-bottom topography (Dougherty \& Stephen 1991), the width and depth of the SOund Fixing and Ranging (SOFAR) channel (Munk 1974) over the spatial range and across the seasons covered by the SPPIM array, and other unstudied and yet unknown factors may also all play a role in the conversion of energy (Tolstoy \& Ewing 1950; Okal 2008) and in determining the local ambient noise field (Gualtieri et al. 2019).

Looking beyond simple magnitude and distance considerations we cannot yet disentangle the various factors that contribute to the large variance in the rate of return of individual MERMAIDs. No modelling of the true nature of acoustic conversions under our floats has been performed, indeed even the bathymetry is not well 
Sampling the mantle under the South Pacific with MERMAID

constrained in some areas under the SPPIM array, nor did we correlate wave or storm records with our seismic data (likely the main driver of time-variable background noise levels, see, e.g. Webb \& Cox 1986; Babcock et al. 1994; Gualtieri et al. 2013; Farra et al. 2016). It will be interesting to probe whether the MERMAIDs that sent the least data spent the most time in the noisiest regions, stalled over areas of the seafloor with inefficient seismic-acoustic coupling, were muted by some other unidentified disturbance, or were influenced by some combination of all of these factors. Future work will benefit from simulation of seismic-acoustic conversions into realistic ocean layers at (relatively high) $\sim 1 \mathrm{~Hz}$ frequencies (e.g. Fernando et al. 2020).

\subsection{Earthquake catalogue completeness and statistics}

We now move to comparing our seismic catalogue with other global catalogues available at the time. How 'complete' is our catalogue compared to those others? Conversely, how many global earthquakes did MERMAID miss? No catalogue can include all earthquakes of all magnitudes, globally (Kagan 2003), but here we do take the number of events recorded in global seismic catalogues to be the true population size against which we will derive completeness statistics.

Fig. 8 plots the MERMAID earthquake catalogue, both by the rate of return considering the entire fleet, and in sum considering each float individually. It further breaks these numbers down by magnitude ranging from $M 5$ in Figs 8(a) and (b) through $M 8$ in Figs $8(\mathrm{~g})$ and (h). The stem plots in the left-hand column show the number of MERMAIDs reporting each positively identified earthquake as a function of time, beginning from the first deployment of P0008 on 5 August 2018 through the end of 2019. Note that the Princeton fleet of 16 MERMAIDs was not completed until 14 September 2018, marked by a dashed vertical line. The histograms in the right-hand column aggregate these data over time, but separate them by float and by magnitude range.

We represent missed events, not reported by any MERMAID, as crosses placed below the zero line. For example, Fig. 8(e) shows that of all $M 7$ earthquakes that occurred globally while the complete Princeton array was deployed, three remained unreported. Conversely, Fig. $8(\mathrm{~g})$ shows that no events were missed in the magnitude range $M 8+$ (recall that only five MERMAIDs where deployed during the first such event, and it was reported by all five). So many M 5-5.9 events went undetected that rather than plotting them in Fig. 8(a) the mean miss rate (around 4 events per day) is reported below the zero line. Note the different scaling of the ordinate axes in Fig. 8, which highlights the fact that the rate of return of identified earthquakes correlates strongly with magnitude. Finally, in each of the stem plots one event is highlighted in black. These are the events reported by the greatest number of MERMAIDs within each magnitude range, as previously rendered in the record sections of Fig. 5.

The histograms in Fig. 8 parse the cumulative return per float. Fig. 8(b; $M$ 5-5.9) makes clear the observation of Table 1 that P0008 outpaced all the other floats in terms of reporting identifiable earthquakes (even after adjusting for its longer deployment duration, which we do address in Tables 2-6), which we attribute to its geographic proximity to the Tonga Trench, as mentioned in Section 4.2. The complementary distribution for $M 4-4.9$ earthquakes is not shown because most of those light events were missed. Note, however, that over 80 percent of those positively identified were reported by MERMAID P0008.
Table 2. Global $M$ 4-4.9 earthquakes, reported or missed by MERMAID.

\begin{tabular}{lccccccc}
\hline & & & percent & & & & \\
MER. & \# EQ & $\#$ ID & ID & $\frac{\# \text { ID }}{\mathrm{yr}}$ & $\frac{\mathbb{E}[\mathrm{ID}]}{5 \mathrm{yr}}$ & $\frac{\mathbb{E}[\# \mathrm{ID}]}{\overline{\mathrm{yr}}}$ & $\frac{\mathbb{E}[\# \mathrm{ID}]}{5 \overline{\mathrm{yr}}}$ \\
\hline P0008: & 14535 & 73 & 0.5 & 52 & 260 & 61 & 306 \\
P0009: & 14496 & 9 & 0.1 & 6 & 32 & 8 & 38 \\
P0010: & 14475 & 6 & 0.0 & 4 & 21 & 5 & 25 \\
P0011: & 14420 & 0 & 0.0 & 0 & 0 & 0 & 0 \\
P0012: & 14379 & 0 & 0.0 & 0 & 0 & 0 & 0 \\
P0013: & 13559 & 0 & 0.0 & 0 & 0 & 0 & 0 \\
P0016: & 13489 & 0 & 0.0 & 0 & 0 & 0 & 0 \\
P0017: & 13464 & 0 & 0.0 & 0 & 0 & 0 & 0 \\
P0018: & 13430 & 0 & 0.0 & 0 & 0 & 0 & 0 \\
P0019: & 13371 & 0 & 0.0 & 0 & 0 & 0 & 0 \\
P0020: & 13315 & 0 & 0.0 & 0 & 0 & 0 & 0 \\
P0021: & 13256 & 0 & 0.0 & 0 & 0 & 0 & 0 \\
P0022: & 13223 & 0 & 0.0 & 0 & 0 & 0 & 0 \\
P0023: & 13151 & 0 & 0.0 & 0 & 0 & 0 & 0 \\
P0024: & 13146 & 0 & 0.0 & 0 & 0 & 0 & 0 \\
P0025: & 13115 & 0 & 0.0 & 0 & 0 & 0 & 0 \\
\hline Total: & 218824 & 88 & & 63 & 313 & 74 & 369 \\
Mean: & 13677 & 6 & $\ll 1$ & 4 & 20 & 5 & 23 \\
\hline
\end{tabular}

Table 3. Global M 5-5.9 earthquakes, reported or missed by MERMAID.

\begin{tabular}{lccccccc}
\hline & & & per cent & & & & \\
MER. & \# EQ & \# ID & ID & $\frac{\# \mathrm{ID}}{\mathrm{yr}}$ & $\frac{\mathbb{E}[\mathrm{H} \mathrm{ID}]}{5 \mathrm{yr}}$ & $\frac{\mathbb{E}[\# \mathrm{ID}]}{\overline{\mathrm{yr}}}$ & $\frac{\mathbb{E}[\# \mathrm{ID}]}{5 \overline{\mathrm{yr}}}$ \\
\hline P0008: & 2245 & 64 & 2.9 & 46 & 228 & 46 & 230 \\
P0009: & 2242 & 34 & 1.5 & 24 & 121 & 25 & 123 \\
P0010: & 2240 & 34 & 1.5 & 24 & 121 & 25 & 123 \\
P0011: & 2230 & 15 & 0.7 & 11 & 54 & 11 & 54 \\
P0012: & 2222 & 9 & 0.4 & 6 & 32 & 7 & 33 \\
P0013: & 2096 & 4 & 0.2 & 3 & 15 & 3 & 15 \\
P0016: & 2085 & 3 & 0.1 & 2 & 11 & 2 & 12 \\
P0017: & 2081 & 1 & 0.0 & 1 & 4 & 1 & 4 \\
P0018: & 2070 & 0 & 0.0 & 0 & 0 & 0 & 0 \\
P0019: & 2051 & 0 & 0.0 & 0 & 0 & 0 & 0 \\
P0020: & 2039 & 0 & 0.0 & 0 & 0 & 0 & 0 \\
P0021: & 2036 & 0 & 0.0 & 0 & 0 & 0 & 0 \\
P0022: & 2032 & 0 & 0.0 & 0 & 0 & 0 & 0 \\
P0023: & 2019 & 9 & 0.4 & 7 & 35 & 7 & 36 \\
P0024: & 2019 & 1 & 0.0 & 1 & 4 & 1 & 4 \\
P0025: & 2013 & 1 & 0.0 & 1 & 4 & 1 & 4 \\
\hline Total: & 33720 & 175 & & 126 & 629 & 128 & 638 \\
Mean: & 2108 & 11 & $\sim 0.5$ & 8 & 39 & 8 & 40 \\
\hline
\end{tabular}

We reiterate that these statistics are plotted against the NEIC PDE Bulletin of global events, which itself is incomplete. There exists a complementary set of uncatalogued events that remain undetected by the current global seismic network. MERMAID records some of those events and the analysis of those records is the target of future work, but we can report some statistics here: there remain 245 records after the removal of presumed instrument glitches from the list of unidentified MERMAID seismograms. That results in an upper-bound estimate of $\sim 15$ additional uncatalogued earthquakes (not necessarily unique) detected by every MERMAID during the SPPIM deployment so far, or about 1 additional uncatalogued earthquake detected by every MERMAID each month.

\subsection{Estimating the final size of the earthquake catalogue}

With Table 1 we found that, between deployment in late 2018 and the end of 2019, each MERMAID in our fleet returned an average of 43 identified seismograms, or about 31 per year. With Fig. 8 we 
Table 4. Global $M$ 6-6.9 earthquakes, reported or missed by MERMAID.

\begin{tabular}{lccccccc}
\hline & & & per & & & & \\
MER. & \# EQ & \# ID & cent ID & $\frac{\# \mathrm{ID}}{\mathrm{yr}}$ & $\frac{\mathbb{E}[\# \mathrm{ID}]}{5 \mathrm{yr}}$ & $\frac{\mathbb{E}[\# \mathrm{ID}]}{\overline{\mathrm{yr}}}$ & $\frac{\mathbb{E}[\# \mathrm{ID}]}{5 \mathrm{yr}}$ \\
\hline P0008: & 198 & 43 & 21.7 & 31 & 153 & 26 & 132 \\
P0009: & 198 & 42 & 21.2 & 30 & 150 & 26 & 129 \\
P0010: & 198 & 34 & 17.2 & 24 & 121 & 21 & 104 \\
P0011: & 198 & 25 & 12.6 & 18 & 90 & 15 & 77 \\
P0012: & 198 & 22 & 11.1 & 16 & 79 & 14 & 68 \\
P0013: & 181 & 14 & 7.7 & 10 & 52 & 9 & 47 \\
P0016: & 181 & 14 & 7.7 & 11 & 53 & 9 & 47 \\
P0017: & 181 & 13 & 7.2 & 10 & 49 & 9 & 44 \\
P0018: & 181 & 13 & 7.2 & 10 & 49 & 9 & 44 \\
P0019: & 180 & 12 & 6.7 & 9 & 46 & 8 & 41 \\
P0020: & 178 & 7 & 3.9 & 5 & 27 & 5 & 24 \\
P0021: & 178 & 8 & 4.5 & 6 & 31 & 5 & 27 \\
P0022: & 176 & 5 & 2.8 & 4 & 19 & 3 & 17 \\
P0023: & 175 & 9 & 5.1 & 7 & 35 & 6 & 31 \\
P0024: & 175 & 11 & 6.3 & 8 & 42 & 8 & 38 \\
P0025: & 175 & 7 & 4.0 & 5 & 27 & 5 & 24 \\
\hline Total: & 2951 & 279 & & 204 & 1022 & 179 & 894 \\
Mean: & 184 & 17 & $\sim 9.5$ & 13 & 64 & 11 & 56 \\
\hline
\end{tabular}

Table 5. Global $M$ 7-7.9 earthquakes, reported or missed by MERMAID.

\begin{tabular}{lccccccc}
\hline & & & per & & & & \\
MER. & \# EQ & \# ID & cent ID & $\frac{\# \mathrm{ID}}{\mathrm{yr}}$ & $\frac{\mathbb{E}[\# \mathrm{ID}]}{5 \mathrm{yr}}$ & $\frac{\mathbb{E}[\# \mathrm{ID}]}{\overline{\mathrm{yr}}}$ & $\frac{\mathbb{E}[\# \mathrm{ID}]}{5 \mathrm{yr}}$ \\
\hline P0008: & 20 & 7 & 35.0 & 5 & 25 & 5 & 23 \\
P0009: & 20 & 9 & 45.0 & 6 & 32 & 6 & 30 \\
P0010: & 20 & 9 & 45.0 & 6 & 32 & 6 & 30 \\
P0011: & 20 & 11 & 55.0 & 8 & 39 & 7 & 36 \\
P0012: & 20 & 12 & 60.0 & 9 & 43 & 8 & 40 \\
P0013: & 17 & 11 & 64.7 & 8 & 41 & 9 & 43 \\
P0016: & 17 & 8 & 47.1 & 6 & 30 & 6 & 31 \\
P0017: & 17 & 8 & 47.1 & 6 & 30 & 6 & 31 \\
P0018: & 17 & 6 & 35.3 & 5 & 23 & 5 & 23 \\
P0019: & 16 & 6 & 37.5 & 5 & 23 & 5 & 25 \\
P0020: & 16 & 5 & 31.2 & 4 & 19 & 4 & 21 \\
P0021: & 16 & 6 & 37.5 & 5 & 23 & 5 & 25 \\
P0022: & 16 & 6 & 37.5 & 5 & 23 & 5 & 25 \\
P0023: & 16 & 7 & 43.8 & 5 & 27 & 6 & 29 \\
P0024: & 16 & 6 & 37.5 & 5 & 23 & 5 & 25 \\
P0025: & 16 & 7 & 43.8 & 5 & 27 & 6 & 29 \\
\hline Total: & 280 & 124 & & 92 & 461 & 93 & 464 \\
Mean: & 18 & 8 & $\sim 44$ & 6 & 29 & 6 & 29 \\
\hline
\end{tabular}

saw how identifications were distributed across different magnitude ranges. Here we extrapolate those historical data to estimate the final size of the complete MERMAID catalogue considering the anticipated 5-yr lifespan of each instrument. As in Table 1, some of the numbers in the following tables are rounded.

Tables 2-6 break down the rates of identified returns and project for the number of identifications each float is likely to tally in its lifetime. The first column in Tables 2-6 lists the MERMAID serial number. The second quotes the total number of earthquakes that occurred over the deployment duration of that specific float. This number represents the maximum number of earthquakes that each float could have individually identified during its deployment. The third and fourth columns list the number and percentage of those events that were identified. These properly quote the perMERMAID identification rates implied by the histograms in Fig. 8 but which are obfuscated there by differing deployment durations.
Table 6. Global $M$ 8-8.9 earthquakes, reported or missed by MERMAID.

\begin{tabular}{|c|c|c|c|c|c|c|c|}
\hline MER. & \# EQ & \# ID & $\begin{array}{l}\text { per cent } \\
\text { ID }\end{array}$ & $\frac{\# \mathrm{ID}}{\mathrm{yr}}$ & $\frac{\mathbb{E}[\# \mathrm{ID}]}{5 \mathrm{yr}}$ & $\frac{\mathbb{E}[\# \text { ID }]}{\overline{\mathrm{yr}}}$ & $\frac{\mathbb{E}[\# \mathrm{ID}]}{5 \mathrm{yr}}$ \\
\hline P0008: & 2 & 1 & 50.0 & 1 & 4 & 0 & 2 \\
\hline P0009: & 2 & 1 & 50.0 & 1 & 4 & 0 & 2 \\
\hline P0010: & 2 & 2 & 100.0 & 1 & 7 & 1 & 5 \\
\hline P0011: & 2 & 2 & 100.0 & 1 & 7 & 1 & 5 \\
\hline P0012: & 2 & 2 & 100.0 & 1 & 7 & 1 & 5 \\
\hline P0013: & 1 & 0 & 0.0 & 0 & 0 & 0 & 0 \\
\hline P0016: & 1 & 1 & 100.0 & 1 & 4 & 1 & 5 \\
\hline P0017: & 1 & 1 & 100.0 & 1 & 4 & 1 & 5 \\
\hline P0018: & 1 & 1 & 100.0 & 1 & 4 & 1 & 5 \\
\hline P0019: & 1 & 1 & 100.0 & 1 & 4 & 1 & 5 \\
\hline P0020: & 1 & 1 & 100.0 & 1 & 4 & 1 & 5 \\
\hline P0021: & 1 & 1 & 100.0 & 1 & 4 & 1 & 5 \\
\hline P0022: & 1 & 1 & 100.0 & 1 & 4 & 1 & 5 \\
\hline P0023: & 1 & 1 & 100.0 & 1 & 4 & 1 & 5 \\
\hline P0024: & 1 & 1 & 100.0 & 1 & 4 & 1 & 5 \\
\hline P0025: & 1 & 0 & 0.0 & 0 & 0 & 0 & 0 \\
\hline Total: & 21 & 17 & & 13 & 63 & 12 & 61 \\
\hline Mean: & 1 & 1 & $\sim 81$ & 1 & 4 & 1 & 4 \\
\hline
\end{tabular}

The fifth column of Tables 2-6 is analogous to the final column of Table 1, except here it is further parsed by magnitude. The sixth column estimates the expected total number of identified seismograms reported over a 5 -yr lifespan by multiplying the previous column by five. For light and moderate earthquakes especially, this method of estimation is likely sound because they occur so frequently that any annual variability in their sample size is expected to be relatively small. Conversely, great earthquakes occur so infrequently that our projections based upon their statistics only within the time period the SPPIM array could be greatly skewed by anomalous seismicity rates.

To combat the potential issue of anomalous sample sizes skewing our projections we assembled a data set of all events catalogued by IRIS from 1985 through to the end 2014. Thirty years of data surely provides a large enough sample size within each magnitude range to converge to the true population values-2014 was far enough in the past to ensure that the International Seismological Centre (2015) catalogue had been reviewed (Bondár \& Storchak 2011) and published (it generally lags behind the NEIC PDE Bulletin by a few years), and 1985 was still recent enough to ensure that a robust and relatively modern seismic network was installed globally, which all but guaranteed that the resultant catalogues would be relatively complete. Over that 30-yr span there were a total of $365378 \mathrm{M} \mathrm{4}$, $48511 M 5,3650 M 6,396 M 7$ and $28 M 8$ earthquakes, resulting in an average of $12179 M 4,1617 M 5,122 M 6,13 M 7$ and $1 M 8$ earthquakes per year. We use those numbers to compute the values in the final two columns of Tables $2-6$, where the overline, $\overline{\mathrm{yr}}$, denotes such an 'average' year. In column seven we multiplied these average seismicity rates by the percentage of the total that each float identified (column four) to compute a second estimate of the expected total number of identified seismograms that any individual MERMAID may return in a year. In column eight we again multiplied this value by five to project for the final number of earthquakes each float may be expected to identify in its lifetime.

The penultimate row of Tables 2-6 tallies the totals of the columns, and the ultimate row reports their means. The last value in the final row gives our best estimate of the number of identified earthquakes that any given MERMAID will report within that magnitude range over its lifetime. We calculate $23 M 4,40 M$ 5, $56 M 6,29 M 7$ and $4 M 8$ earthquakes, or just over 150 earthquakes in total. For our fleet of 16 this approaches 2500 identifications. As 
(a)

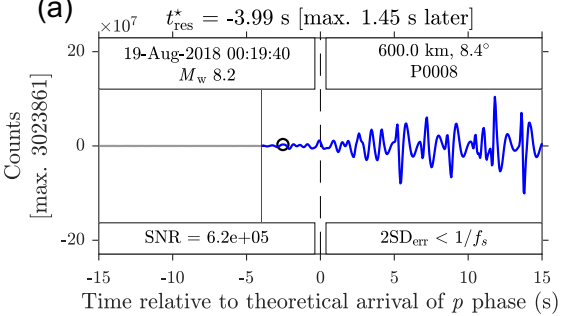

(d)

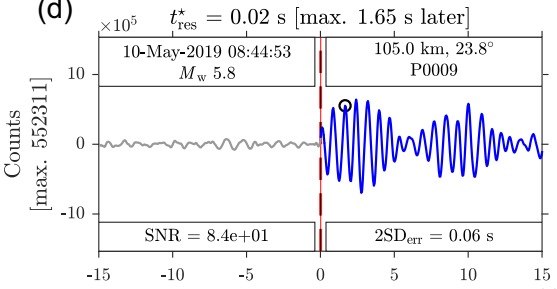

Time relative to theoretical arrival of $P$ phase (s)

(g)

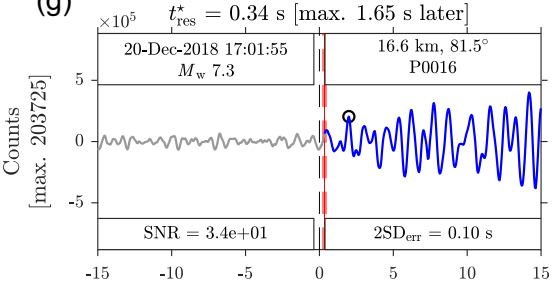

Time relative to theoretical arrival of $P$ phase $(\mathrm{s})$

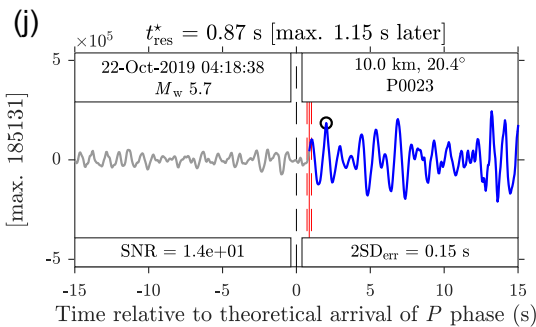

(b)

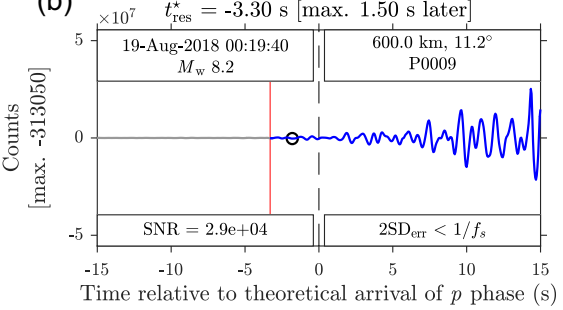

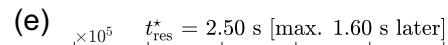

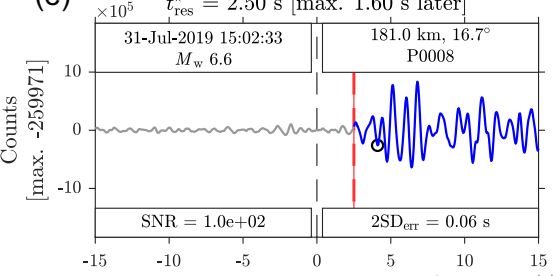

Time relative to theoretical arrival of $P$ phase (s)

(h)

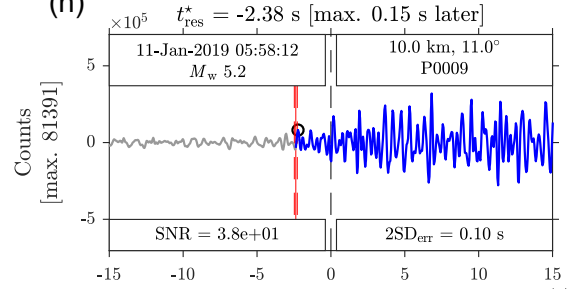

Time relative to theoretical arrival of $P$ phase (s)

(k)

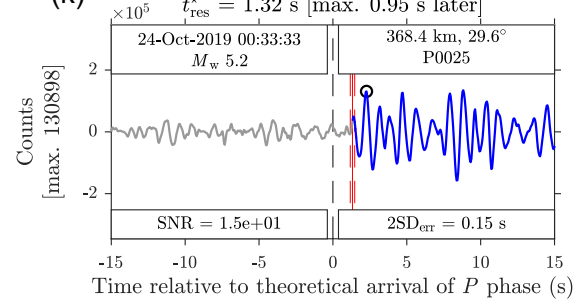

(c)

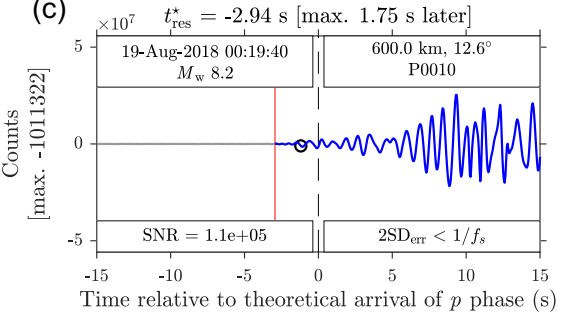

(f)

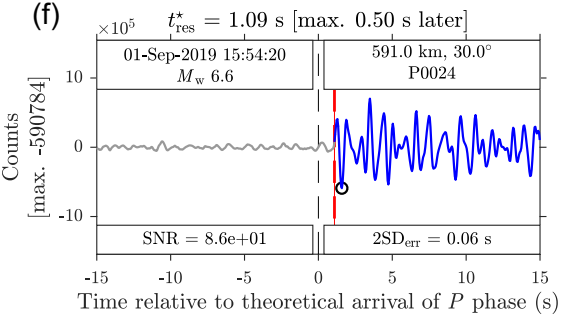

(i)

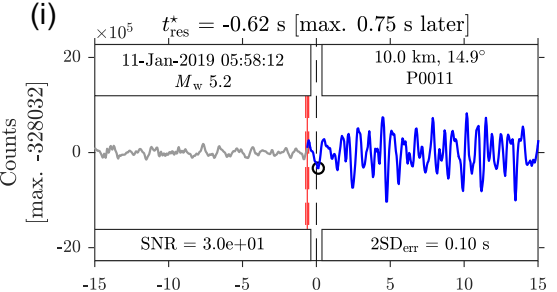

Time relative to theoretical arrival of $P$ phase (s)

(l)

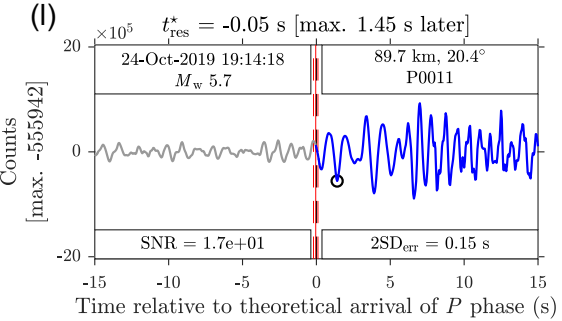

Figure 9. MERMAID seismograms within a $30 \mathrm{~s}$ window aligned on the theoretical first-arriving phase $(P$ or $p)$ in ak135 models adjusted for bathymetry and cruising depth. All seismograms are in counts, filtered between 1 and $5 \mathrm{~Hz}$. In each, the solid red vertical line marks our automated pick and hence the traveltime residual in the individually-adjusted ak135 model (see the Appendix). The estimated uncertainty on our pick using Method 1 of Simon et al. (2020) is shown as dashed vertical lines at \pm two-standard deviations, $2 \mathrm{SD}_{\text {err }}$. Listed above each panel is the adjusted traveltime residual, and the delay between our pick and the time (circled) of the maximum (or minimum) amplitude of the signal (whose rounded value is reported within the brackets on the ordinate). Insets clockwise from the top left-hand side: earthquake origin date and time and magnitude; depth, distance, and recording MERMAID; estimated SNR of the seismogram; and twice the standard-deviation error estimate of our pick.

we have seen, the variance in the rate of return among the floats is large. For example P0008, with its 188 identified events, has already surpassed its expected lifetime-total return.

As in Section 4.2 we conclude that it is likely the geographic location, the frequency and severity of nearby storms, and perhaps the geological seafloor setting above which MERMAID drifts, that most influence the rate of return of identified seismograms by any individual float. This point is well made in Table 2 columns one through three, where we see that P0011 could have recorded just about as many $M 4$ earthquakes as P0008, but the former identified none and the latter identified 73 .

\section{THE MERMAID RESIDUALS CATALOGUE}

Having understood MERMAID's ability to detect global earthquakes, we now move to discussing the seismograms themselves.
In particular, we are interested in the high-precision picking of firstarriving $P$ or $p$ waves, the estimation of uncertainty about those times, and what MERMAID residuals against various velocitymodel predictions may tell us about mantle structure.

\subsection{Traveltime residuals and their uncertainties}

Fig. 9 shows 12 MERMAID seismograms and their traveltime residuals and uncertainty estimates in ak135 models adjusted for local bathymetry and cruising depth following the procedures of Simon et al. (2020), described and expanded upon in the Appendix. The rows are ordered from low to high uncertainty. The first three seismograms (Figs 9a-c) are the lowest-uncertainty records in the MERMAID catalogue, and the final three (Figs 9j-1) display seismograms with picking uncertainties equal to $0.15 \mathrm{~s}$. The middle rows, Figs 9(d)-(f) and (g)-(i), show seismograms for which the corresponding uncertainties straddle the 33rd and 66th percentiles between these two uncertainty bounds, respectively. Each 
panel of Fig. 9 plots $30 \mathrm{~s}$ of one MERMAID seismogram with its timing relative to the theoretical onset of the first-arriving $P$ or $p$ wave (dashed black vertical line at $0 \mathrm{~s}$ ). After tapering and filtering, these segments yielded our picks (solid red vertical lines, with uncertainties shown as dashed red vertical lines at $\pm 2 \mathrm{SD}_{\text {err }}$ along the time axes) of the first arriving $P$ or $p$ waves, with their corresponding adjusted residuals quoted above each panel.

The portion before our arrival-time pick is considered 'noise' and coloured grey, while the portion after our pick is considered 'signal' and coloured blue. Thus, the SNRs reported here, and for the remainder of the study, are computed as in eq. (1) but we specifically only consider $30 \mathrm{~s}$ windows like those shown in Fig. 9, and we compute the estimated variances directly from the grey and coloured segments as partitioned by our picks. On each seismogram we circle the maximum absolute amplitude of the first-arriving phase. Its value and the delay time between it and our first-arrival pick are reported in brackets outside the left ordinate and upper abscissa axes, respectively. We define the first-arriving phase window to be the segment of the seismogram starting at our arrival-time pick and ending $1.75 \mathrm{~s}$ later. We chose $1.75 \mathrm{~s}$ because it is longer than our minimum-retained phase of $1 \mathrm{~Hz}$, ensuring that we capture at least one complete cycle, and it is shorter than $2 \mathrm{~s}$, the estimated roundtrip traveltime of the surface-reflected phase (the large-amplitude, opposite-polarity 'ghost'). Earthquake parameters including origin time, magnitude, depth and distance to the recording MERMAID are noted in the upper inset boxes within each panel. Our estimated signal criteria of the SNR of the seismogram and twice the standard deviation of the timing uncertainty on the residual are quoted in the lower inset boxes.

\subsection{Comparing MERMAID against nearby island stations}

To prove the tomographic utility of MERMAID residuals we compare their statistics against measurements made for the same events at island stations located in the oceanographic neighbourhood of the slowly dispersing SPPIM array. We compare our uncalibrated seismoacoustic pressure records (the MERMAID 'seismograms') with velocity seismograms from land-based seismic sensors.

We compare the MERMAID catalogue of traveltime residuals, SNR estimates and traveltime uncertainties with a similar catalogue that we construct for island seismic stations in the vicinity of MERMAID. Fig. 1 showed MERMAID's oceanic neighbourhood. At 32 million $\mathrm{km}^{2}$ it spans a large portion of the South and some of the North Pacific, nearly 6.5 per cent of Earth's surface, or roughly double the area of Russia. The Appendix details which stations were used for these comparisons and how we retrieved and processed their data. We picked all traveltime residuals using the same methodology regardless of station type.

We compare all measurements against the 1-D ak135 model. We perform this simple 1-D comparison first to show that the distributions of residuals from more traditional seismic instruments and MERMAID agree well, indicating that MERMAID is returning tomographically useful data. Later we recompute MERMAID residuals in the fully 3-D elliptical LLNL-3DGv3 crust and mantle model of Simmons et al. (2012) to interrogate the geographic distribution of velocity perturbations in Earth's mantle as recorded by MERMAID.

Fig. 10 shows the distributions of $P$ - and $p$-wave traveltime residuals (top row), their SNRs (middle row), and their uncertainty estimates (bottom row), for traditional seismometers, MERMAID and
Raspberry Shake stations, left, middle and centre, respectively. A vertical dashed line marks the mean in each histogram.

The top row of Fig. 10 plots the traveltime residuals for all firstarriving $P$ and $p$ waves with onsets within $\pm 10 \mathrm{~s}$ of their ak135 predictions. For MERMAID (Fig. 10b), we use the adjusted traveltimes as explained in the Appendix and label them appropriately as $t_{\text {res }}^{\star}$, while for the traditional (Fig. 10a) and Raspberry Shake stations (Fig. 10c) no adjustments are needed. The only quality control applied to the MERMAID residuals was the rejection of those that exceeded (positively or negatively) the $10 \mathrm{~s}$ cut-off. For the residuals in Fig. 10(a) and Fig. 10(c) we required the additional quality criteria that their SNRs (middle row) must be equal to or greater than the minimum over the MERMAID data set (Fig. 10e), and that their uncertainty estimates (bottom row) must be equal to or smaller than the maximum corresponding value in the MERMAID data set (Fig. 10h).

This selection aims to mimic human intervention on the MERMAID data. Indeed, during manual review often the first author would sometimes reject, for various reasons, a phase-arrival pick that aligned nicely with a theoretical arrival time. Our automated picker, in contrast, reports any signal with an SNR greater than one. Therefore, often by algorithmic necessity the picker will trigger on something that is extremely low-SNR (just above one), which by coincidence also aligns with some theoretical first arrival, but which a human would readily reject (e.g. a reflected phase from a small and distant earthquake). Every single MERMAID seismogram discussed here was reviewed by a human and a phase-arrival was verified to exist, but not every seismogram from the nearby stations was reviewed (rather, each was simply run though the same phase-picking algorithm). Therefore, it was determined that the minimum SNR and the maximum two-standard deviation uncertainty estimates of the identified MERMAID data set could serve to approximately winnow the nearby data to the standards by which the author's eye accepted or rejected a pick. This is clearly an imperfect process, and in doing it we are not implying that noise levels across all three instrument classes are equal (they are not, see the middle row). The number of traces that passed this winnowing process and contributed data to the histograms of Figs 10(a)-(c) is quoted above each panel.

The distribution of first-arrival MERMAID residuals in Fig. 10(b) agrees well with the complementary distribution from traditional seismometers in Fig. 10(a), and to a lesser extent the same distribution computed for the Raspberry Shake stations in Fig. 10(c). All are positively biased, meaning that, on average, the traveltime of the first-arriving $P$ or $p$ wave was delayed compared to the ak135 reference model. The mean of the MERMAID residuals falls between the other two instrument classes. Their standard deviation is smaller than for the other two instrument classes, bolstering our claim that MERMAID reports data useful for seismic tomography in recording tomography-grade $P$ - and $p$-wave arrivals.

The middle row of Fig. 10 displays histograms of the (logarithmic) SNRs of the first-arrival residuals. Note that the data extend beyond the abscissa limits shown. The minimum SNR is identical for all three histograms because it is the smallest SNR in the MERMAID data set and it was used as a threshold for the others. Despite this attempt to winnow the data from nearby stations we believe that we see the result of human intervention in the shape of the MERMAID histogram. The MERMAID SNRs have a broad mode near their mean, and their histogram more slowly ramps up to its maximum than compared with the other two instrument types, decreasing differently. This is likely the result of rejecting lower-SNR picks in the MERMAID data set via the manual review step not 

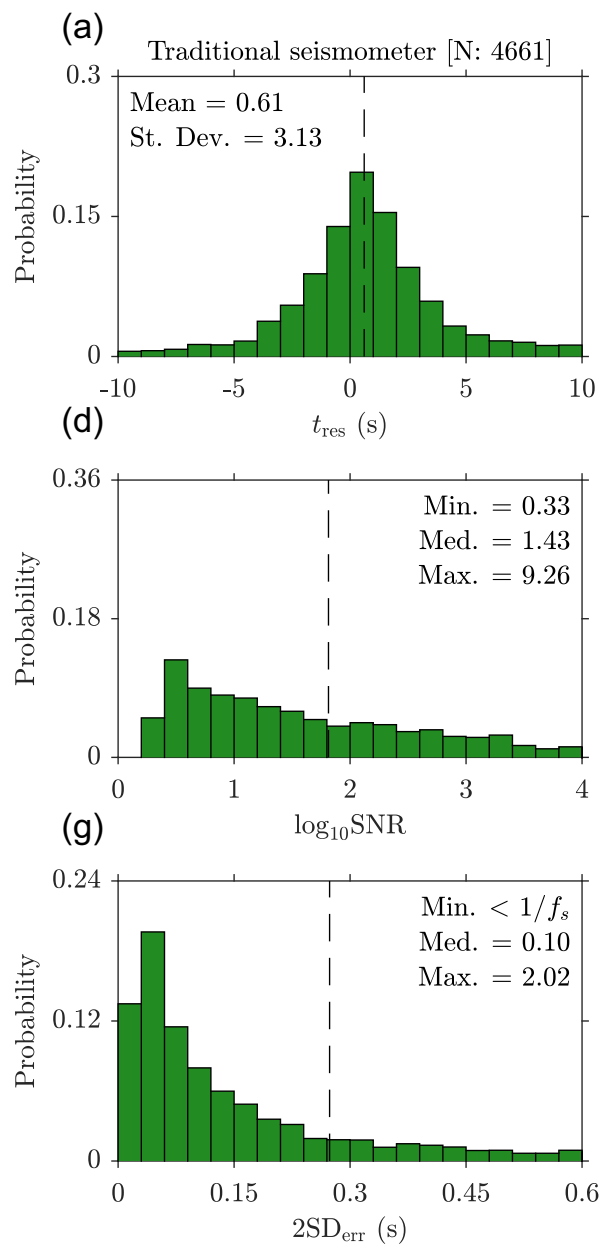

(b)

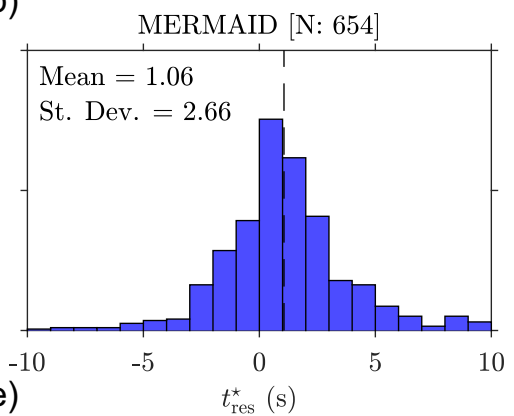

(c)

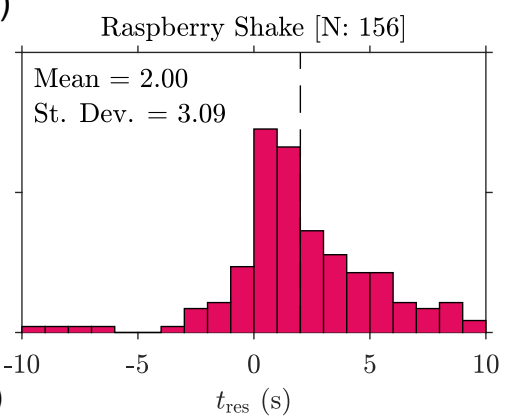

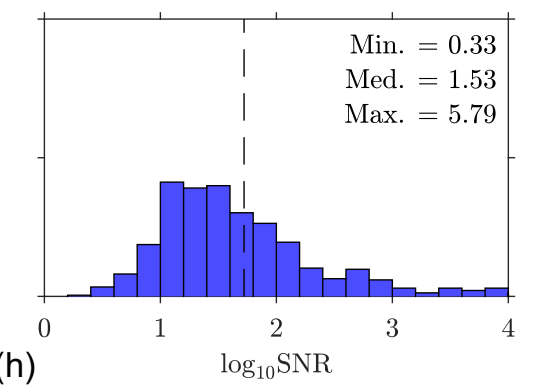

(h)

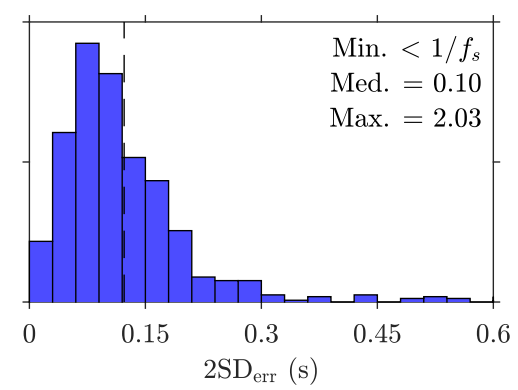

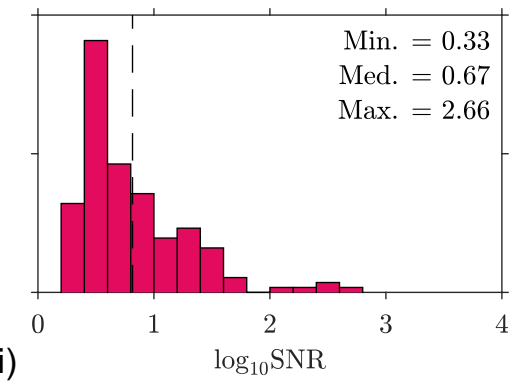

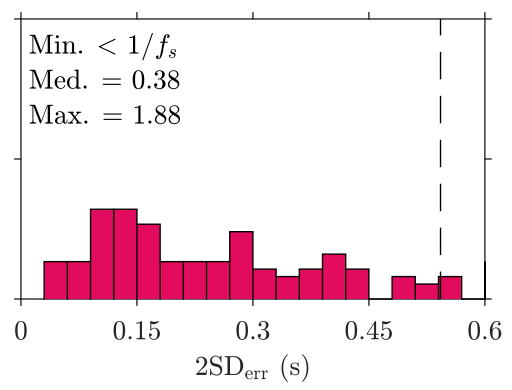

Figure 10. MERMAID traveltime residuals (top row), their SNRs (middle row), and their estimated uncertainties (bottom row) compared to traditional seismometers and Raspberry Shake stations on islands in the neighbourhood of the SPPIM deployment. MERMAID data (middle column; blue) most closely resemble those of the traditional stations (left-hand column; green), and display much higher mean and maximum SNRs, and much lower mean estimated uncertainties, than the Raspberry Shake instruments (right-hand column; raspberry). MERMAID traveltime residuals and their statistics are computed in ak135 models adjusted for bathymetry and recording depth, while those for traditional and Raspberry Shake stations are computed for the standard ak135 model.

applied to the other data. Hence our method of winnowing the traditional and Raspberry Shake data using hard thresholds computed from the MERMAID data set is conservative in retaining a greater proportion of high-noise, high-uncertainty traces than would be the case for manual data reduction.

Generally speaking, MERMAID SNRs fall between those computed from traditional stations and Raspberry Shake instruments. The median SNRs of the MERMAID and traditional data sets are similar, and both are higher than the same statistic for the Raspberry Shake data set. Interestingly, the maximum SNR among the three differs greatly, with that of the traditional stations being much greater than MERMAID, itself greater than Raspberry Shake.

We have plotted all data that passed our winnowing procedure from each instrument class. In Fig. S2 of the Supporting Information we recreate Fig. 10 using only earthquakes for which all three instrument classes had at least one station returning data. The limitation to common events implies a selection of events that occurred after the installation of Raspberry Shake stations, the most data-limited instrument class in our study. Among this subset of the SNRs, traditional seismometers recorded the firstarriving phase with a maximum SNR of $2.6 \times 10^{7}$, MERMAID with a maximum SNR of $6.4 \times 10^{4}$ and Raspberry Shake with a maximum SNR of $4.6 \times 10^{2}$. For reference, using eq. (1) and assuming the same amplitude signal, these results equate to a $26 \mathrm{~dB}$ reduction in the noise level of a traditional station as compared to MERMAID, and a $21 \mathrm{~dB}$ reduction in the noise level of MERMAID compared with Raspberry Shake. Two caveats to consider are that these values do not take differences in epicentral distances into consideration and that MERMAID seismograms can contain high-amplitude reverberations for many tens of seconds after the initial arrival that may artificially inflate the SNRs of those pressure records.

A more detailed comparison of the waveforms recorded by all three instrument classes than may be gleaned from Fig. 5 is given in Figs S3-S5 of the Supporting Information, which plot the 12 highest-SNR seismograms from the three instrument classes, in the same format as Fig. 9, but only considering the data in the common catalogue (as in Fig. S2). From those figures it is immediately obvious that the noise levels for both traditional stations and MERMAID stations are much lower than Raspberry Shake (granted, the former are generally nearer to their respective events), with MERMAID displaying noise levels more akin to traditional stations than Raspberry Shake. 
The bottom row of Fig. 10 shows histograms of the uncertainty estimates, $2 \mathrm{SD}_{\text {err }}$, associated with each first-arrival residual, as developed by Simon et al. (2020) and discussed in the Appendix. These values were quoted in the lower-right legends in each panel of Fig. 9. As in the middle row, the data extend beyond the axis limits. We see that the uncertainties on the residuals associated with both traditional stations in Fig. 10(g) and MERMAID floats in Fig. 10(h) display a satisfying exponential decay, with their mode nearer the lower end of the uncertainty scale. Both enjoy the lowest uncertainties at nearly the same proportion. The distribution of Raspberry Shake uncertainties in Fig. 10(i) is quite different from either of the other instrument classes. It is not obviously peaked at the lower end, and it is approximately uniform across the full range. Furthermore, while the lowest and highest uncertainties corresponding to each instrument class are roughly the same, the medians are quite different, as the value associated with Raspberry Shake is nearly four times that of the other two.

One caveat concerning our method of uncertainty estimation is that for comparisons to be usefully made across various instrument types, all data must be downsampled to the sampling frequency of the lowest-sampled instrument. We estimate uncertainties in terms of samples, converted to time via multiplication with the sampling interval. Therefore, given the same estimated sample uncertainty, the timing-uncertainty associated with a $100 \mathrm{~Hz}$ Raspberry Shake seismogram that has not been downsampled would be reported as being fivefold lower than that associated with a $20 \mathrm{~Hz}$ MERMAID seismogram. In that sense, rather than considering the timinguncertainty estimates output by our method as absolute times, the uncertainties may better serve as relative metrics for comparisons between and across data sets. Practically speaking, they map an SNR to a time, with which the eye may or may not agree, but they nonetheless provide a convenient means to sort and winnow data.

\section{TOWARD SOUTH PACIFIC P-WAVE TOMOGRAPHY}

Having compared the quality of MERMAID residuals to the best data available from permanent island stations in the area, we place them in their geographic context to explore the velocity perturbations that they reveal in the mantle under the South Pacific. In this section we limit ourselves to mantle $P$ waves for use in tomographic inversions. As to the other phases that MERMAID also records, such as shear $(S)$ waves, surface wave trains, $T$ phases, core phases and other hydroacoustic conversions from seismic and non-seismic, for example volcanic, events, see Simon et al. (2021b) and Pipatprathanporn \& Simons (2021).

Fig. 11 plots the highest-quality first-arrival $P$ - and $p$-wave traveltime residuals of our MERMAID data set. As in Fig. 10, we rejected any residuals that exceeded \pm 10 s to ensure that our picker triggered on legitimate phase arrivals and not on other spurious energy. We additionally rejected residuals whose two-standard deviation uncertainty estimates, $2 \mathrm{SD}_{\text {err }}$, exceeded $0.15 \mathrm{~s}$, the limit beyond which the first-author's eye began to distrust the picks and/or when it was felt that the uncertainties were underestimated. For reference, Fig. 9 displays the full range of the data plotted in Figs 11(c) and (d): from the four lowest-uncertainty residuals (top row), through the 33rd and 66th percentiles of uncertainty (second and third row, respectively), to the four highest-uncertainty residuals which passed muster in the bottom row of Fig. 9 (the uncertainty threshold there being $0.15 \mathrm{~s}$ ).
This quality criterion was decided upon after inspecting all seismograms in the MERMAID catalogue. The highest uncertainty among all first-arriving $P$ waves in the catalogue is $2.03 \mathrm{~s}$.

The residuals in Fig. 11 are coded blue for fast (the first arrival is early compared with theory) and red for slow (the first arrival is late), and they are smeared along their ray paths from source to receiver. We plot them against three velocity models: ak135 in Fig. 11(a; eq. A1); ak135 adjusted for bathymetry and MERMAID cruising depth in Fig. 11(c; eq. A2); and the fully elliptical 3D crust and mantle model LLNL-G3Dv3 in Fig. 11(e; eq. A3). In all three cases the initial residuals were computed in the adjusted ak135 model, $t_{\mathrm{ak} 135}^{\star}$, as is shown in Fig. 9, and then each was individually readjusted using the relative traveltime difference between that model and ak135 or LLNL-G3Dv3 to generate Fig. 11(a) and Fig. 11(e), respectively. This means that the residuals shown here were not re-picked using slightly adjusted windows computed in the three different models, which is acceptable because the maximum absolute 3-D-1-D traveltime difference for the residuals plotted in Fig. 11(e) is $4.65 \mathrm{~s}$, well within a $30 \mathrm{~s}$ window centred on the theoretical first arrival.

In total, 506 residuals passed these quality thresholds for the standard 1-D model, 510 for the adjusted 1-D model, and 509 were retained in the 3-D case. The distributions of those residuals are displayed as lighter bars in the histograms to the right of their corresponding smeared-residual maps in Fig. 11. Their means are marked by dashed vertical lines. Data extend beyond the axes limits. Two numbers are bracketed in the upper right-hand corner of each histogram. The first quotes the number of residuals plotted in the histogram, and the second the total number of residuals which passed quality-thresholding and are shown on the corresponding map. The statistics quoted for each histogram were computed using the latter set. The darker bars stacked inside each histogram plot the subset of residuals corresponding to earthquakes greater than magnitude 5.5 and at teleseismic distances between $30^{\circ}$ and $100^{\circ}$.

Starting with the smeared residuals in Fig. 11(a) and their distributions in Fig 11(b), we generally see large positive anomalies (red; delayed) associated with equatorial ray paths, and lower-amplitude negative anomalies (blue; early) associated with more polar ray paths. These data were not corrected for bathymetry or recording depth. Further, the ak135 model used here is spherical and thus does not account for ellipticity (resulting in larger residuals for equatorial than for polar ray paths), or 3-D structure of the crust and mantle. The first point results in an overall mean-shift of around $1 \mathrm{~s}$ for all residuals in the histogram in Fig. 11(b), and the second point adds an additional bias whose geographic distribution is governed by backazimuth. Combined, these obscure the true signal of mantle-velocity anomalies that MERMAID records. The teleseismic subset of residuals numbers 215 and they have a larger average delay of $2.71 \mathrm{~s}$.

The residuals in Figs 11(c) and (d) have been adjusted for bathymetry and MERMAID cruising depth, though they remain in the spherical ak135 velocity model. As such, the mean-shift in Fig. 11(b) has been reduced by over $1 \mathrm{~s}$ in Fig. 11(d), but the signal of Earth's ellipticity remains visible in Fig. 11(c). In fact, that signal is now more pronounced in the North Pacific, with those data generally displaying negative residuals before applying the adjustment. As in the unadjusted 1-D case the subset of teleseismic residuals represented by the darker bars in the histogram shows a higher average bias than the combined data set at $1.64 \mathrm{~s}$, now determined among 217 residuals.

Finally, the residuals presented in the penultimate row of Fig. 11 are the closest yet to the real signal of velocity perturbations within 
(a)

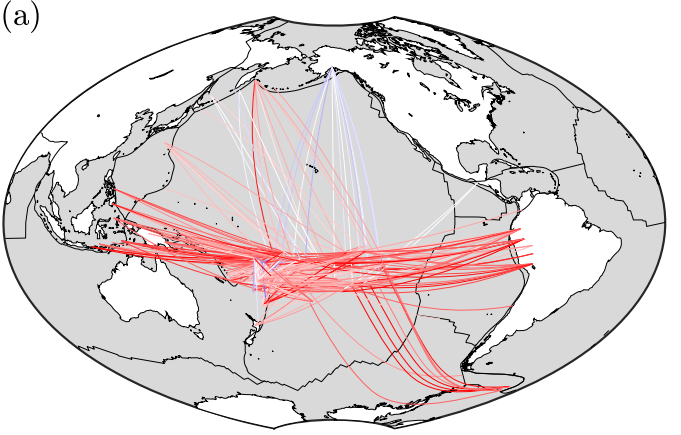

(c)

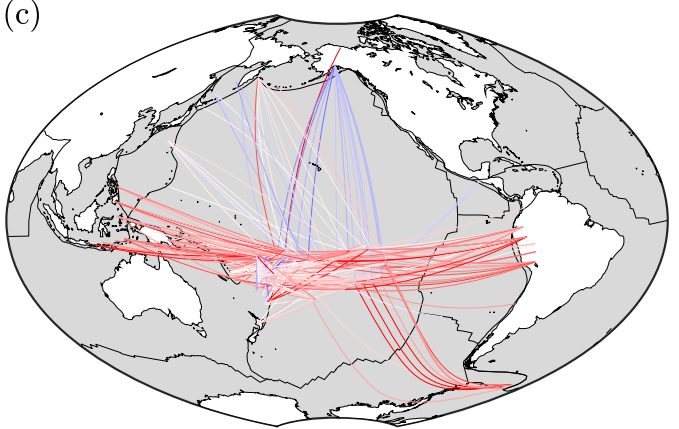

(e)

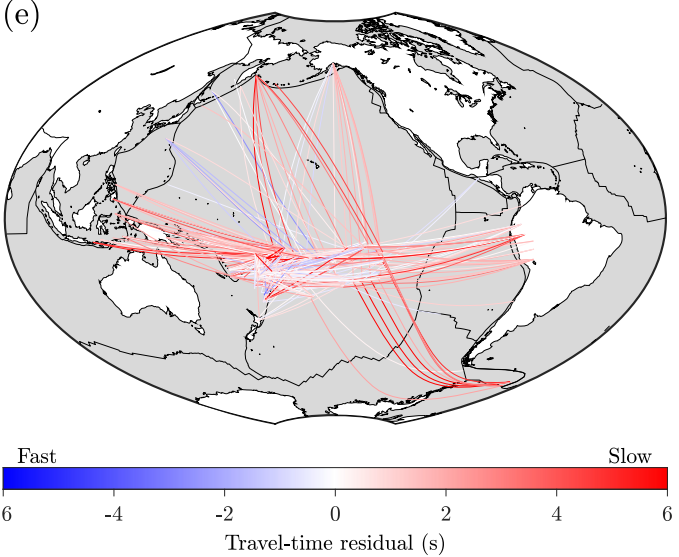

(g)

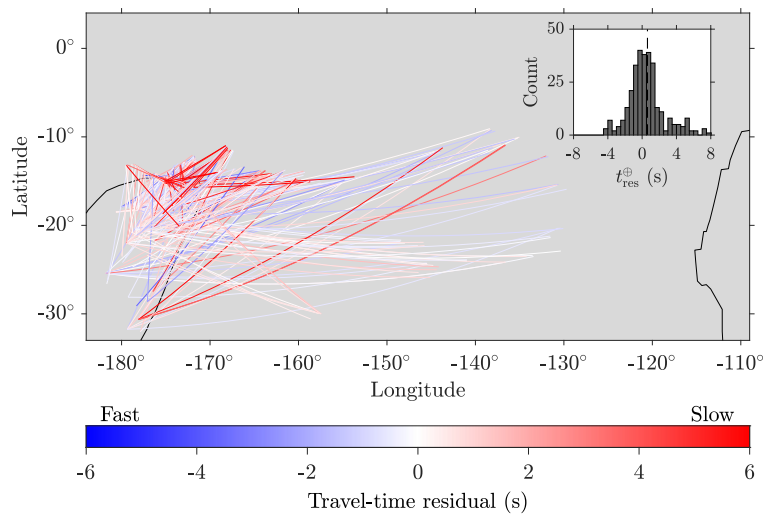

(b)

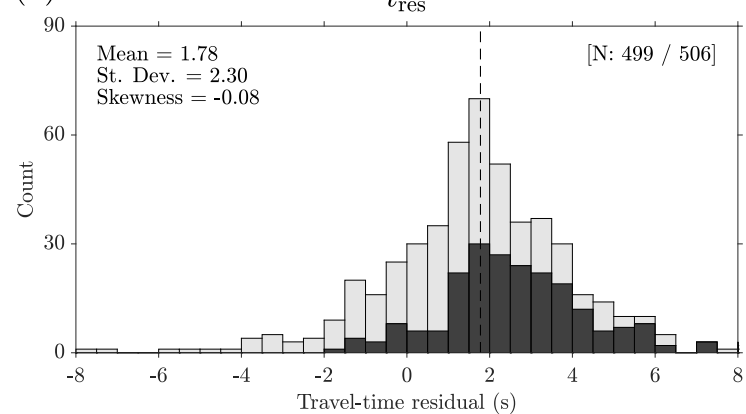

(d)

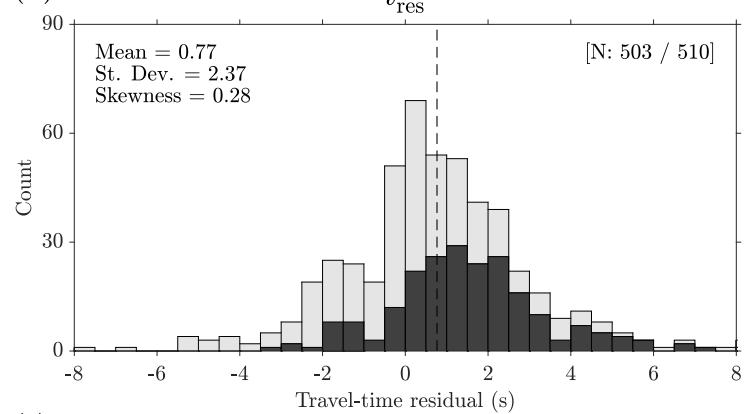

(f)

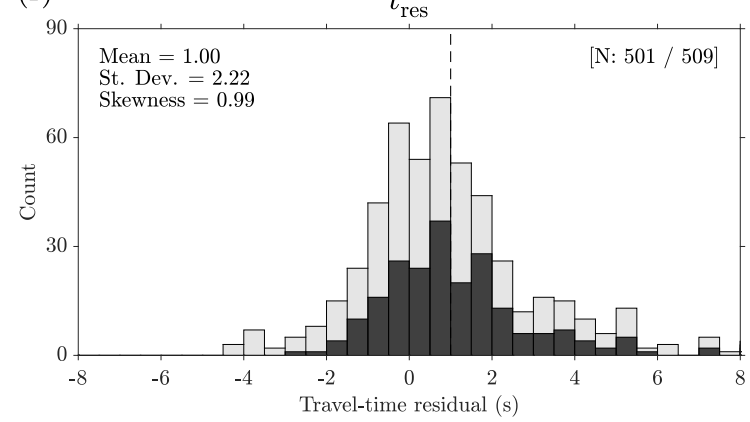

(h)

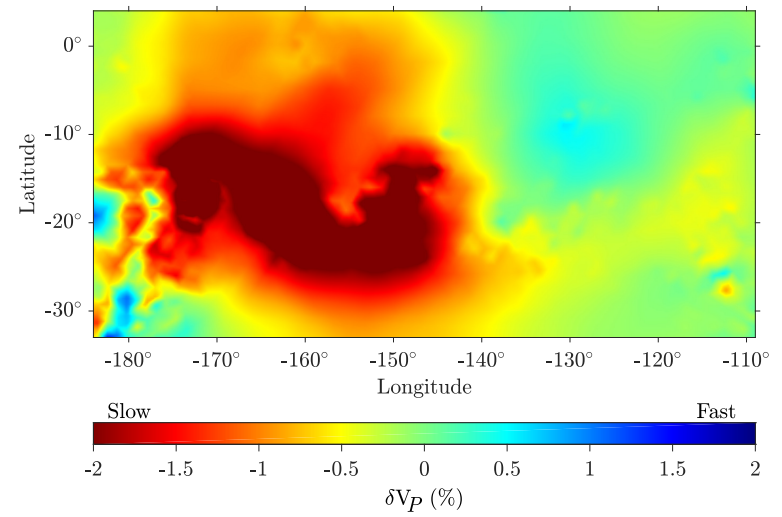

Figure 11. Smeared traveltime residuals computed against ak135 (a; eq. A1), ak135 corrected for bathymetry and MERMAID cruising depth (c; eq. A2), and the Simmons et al. (2012) model LLNL-G3Dv3 (e; eq. A3), and the distributions of those residuals in (b), (d), and (f), respectively. Here we show only the highest-quality residuals in the MERMAID data set: those with maximum two-standard deviation estimated uncertainties, $2 \mathrm{SD}_{\text {err }}$, smaller than $0.15 \mathrm{~s}$ (the final row of Fig. 9 shows the three 'worst' seismograms that made the cut). The colourbar is in units of absolute time, with its colours encoding the residual between our pick and the theoretical arrival time of the reference model (blue is fast, red is slow). Map (e) and its corresponding histogram (f) include 3-D mantle and ellipticity corrections absent in the two prior sets, and thus the residuals shown there are the truest picture yet of the velocity perturbations recorded by MERMAID. Finally, (g) plots only the ray paths in (e) that are entirely contained in the neighbourhood of the SPPIM array, and (h) plots $P$-wave velocity perturbations within the same region in LLNL-G3Dv3 at $500 \mathrm{~km}$ depth. 
the Earth's mantle. They are computed against the fully-3-D and elliptical crust and mantle model LLNL-G3Dv3. Immediately we notice the removal of the signal of Earth's ellipticity; the ray paths through the North Pacific no longer display generally large negative anomalies, and residuals smeared along equatorial ray paths see their generally large positive residuals lowered slightly. The map is still very red, however, implying that the majority of the 3-D residuals recorded by MERMAID display positive, slow anomalies for all back-azimuths. Fig. 11(f) proves this to be the case, showing that, on average, the residuals recorded by MERMAID in the South Pacific are $1 \mathrm{~s}$ late compared to LLNL-G3Dv3. As before, that delay grows when considering only the teleseismic subset, increasing to $1.17 \mathrm{~s}$ among 216 residuals. The final row of maps in Fig. 11 offer zoom ins around the boundary of our SPPIM array (Figs 1b and 4). The left-hand map plots only those ray paths are that are wholly contained in this region, and the map at right shows $P$-wave velocity perturbations in the LLNL-G3Dv3 model at $500 \mathrm{~km}$ depth, near the average maximum depth sensed by the residuals in Fig. 11(g). The red 'seahorse' in this map further illustrates the point made in Fig. 4, namely that the mantle under the South Pacific around and below our SPPIM array is characterized by anonymously slow seismic velocities. The average delay of the regional subset of MERMAID data in Fig. 11(g) is $0.62 \mathrm{~s}$ among 309 residuals.

The darker subset of teleseismic residuals in Figs 11(b), (d) and (f) were winnowed so that their statistics could be directly compared with data collected during the Polynesia Lithosphere and Upper Mantle Experiment (PLUME; Barruol 2002) and broadband ocean bottom seismographs (BBOBS; Suetsugu et al. 2005) experiments, which saw the deployment of 10 ocean-island and 10 OBS stations in French Polynesia between 2001 and 2005 (Suetsugu et al. 2009). The resulting teleseismic $P$-wave data set including traces from PPTF, PTCN and RAR totaled 1477 residuals corresponding to 121 earthquakes (Tanaka et al. 2009a). After correcting for deployment length $(\sim 1.3 \mathrm{yr}$ for MERMAID versus a combined $\sim 1.8 \mathrm{yr}$ when the BBOBS and PLUMES arrays overlapped) and instrument count (16 versus 23; this normalization presumes OBS-detection rates similar to island stations, potentially a poor assumption) this amounts to around 10 high-quality (Fig. 9) teleseismic residuals retained per MERMAID per year compared with around 35 for BBOBS and PLUME. However, unlike the BBOBS and PLUME data set, we were not privy to continuous multimonth time-series, and we were instead presented with data segments preselected for us by the onboard detection algorithm. As such we are confident that we would bolster the MERMAID catalogue with appropriate data requests from its buffer.

Fig. 11 shows that, more often than not, MERMAID recorded seismic waves that traversed regions of the mantle more slowly than predicted. Interestingly, the distribution of these residuals in Fig. 11(f) has a higher mean than the analogous distribution for the adjusted 1-D model in Fig. 11(d). It is also satisfying to note that adjustment to the 3-D model lowered their standard deviation to the smallest value (by a small margin) among all three models. Further, like the other histograms in Fig. 11, this one displays positive skewness but, most interestingly, it exhibits the largest positive skewness among all three (338 of the 509 residuals plotted are positive). Many tomographic inversions somewhat underestimate the magnitude of velocity anomalies due to the inversion methods used (Burdick \& Lekic 2017), thus it is possible that our observations are illuminating stronger slow anomalies in the mantle, possibly associated with the LLVP. However, importantly, we have not accounted for timing errors caused by earthquake mislocation in any of the figures. That remains a vital pre-processing step to be completed before these data are used for tomographic inversion. Thus, while we are confident in the general trend of delayed residuals in our study area, we are as yet unable to speculate on their specific geographic significance. Indeed, the colours in the maps of Fig. 11 could be as influenced by earthquake mislocation as they are by the signal of Earth's mantle (see especially fig. 3b of Hosseini et al. 2020).

\section{CONCLUSIONS}

We described a new seismic instrument, the third-generation MERMAID, which records earthquakes and transmits their seismograms in near real-time from the global oceans. The robotic floats dive to $1500 \mathrm{~m}$ depth below the sea surface and passively drift with the currents while monitoring the ambient acoustic wavefield, surfacing only to relay seismic data, their location, and to download new command files. We discussed the South Pacific Plume Imaging and Modeling (SPPIM) project, which has launched an array of 50 MERMAIDs in the South Pacific Ocean, deployed and maintained by a global consortium, EarthScope-Oceans. The array was completed in August 2019, and as of this writing 46 MERMAIDs are reporting data (see http://earthscopeoceans.org), and will be for many years to come. We highlighted the time-variable nature of the locations of the subset of 16 Princeton-operated MERMAIDs, from their deployments in August and September 2018 through to the end of 2019, whose data were the focus of this study.

We implemented a workflow to process the continuous data stream of incoming seismograms and match them with earthquakes in global catalogues. We reported on the quality and size of the MERMAID earthquakes catalogue, a data product of this study, built up over 16 months of deployment. Our MERMAIDs averaged around 31 event detections per year, equating to more than 150 over their projected 5-yr lifespan, though we found these numbers to be highly variable between different MERMAIDs, which we hypothesized to be largely controlled by their proximity to areas with different earthquake rates and noise regimes (e.g., frequent storms). We discussed the statistics of completeness for our MERMAID seismic catalogue and parsed its numbers by magnitude to reveal the types of earthquakes to which MERMAID proved itself most sensitive. For 'typical' global earthquakes, an 'average' MERMAID had around a 0.5 per cent chance of recording a $M 5$, a 9.5 per cent chance of a recording a $M 6$, a 44 per cent chance for an $M 7$ and an 81 per cent chance of recording a $M 8$ earthquake.

We used a procedure to pick, with high precision, the arrival times of phases in MERMAID seismograms, and to estimate their uncertainties. We compared our catalogue of first-arrival residuals, another data product of this study, against a similarly derived catalogue computed using all available seismic instruments in the general vicinity of the SPPIM deployment. In all, we collected nearly 9000 seismograms from 25 island stations, corresponding to the 288 unique earthquakes recorded by MERMAID. We compared the distributions of first-arrival traveltime residuals, SNRs, and traveltime uncertainties to traditional seismic stations and Raspberry Shake instruments and found that MERMAID had more in common with the former than the latter, proving that MERMAID is indeed recording tomographically useful data.

We winnowed our set of first-arrival $P$ - and $p$-wave traveltime residuals down to the highest-quality subset - just over 500 pickswhich we compared against the fully-3-D and elliptical model LLNL-G3Dv3. We found that, on average, those phase arrivals at MERMAID were delayed by $1 \mathrm{~s}$, revealing that the novel ray paths sampled in this study navigated slow regions of the Earth's 
mantle. We furthermore found that bias increased to $1.17 \mathrm{~s}$ when only the subset of teleseismic events was considered. We displayed these residuals smeared along their ray paths to gain a geographic sense for the signature of those velocity anomalies under the South Pacific. These residuals, their weights being dictated by the associated uncertainties computed here, will form the basis of future tomographic inversions to probe the structure beneath the South Pacific Superswell.

\section{ACKNOWLEDGEMENTS}

This work was supported in part by the National Science Foundation (NSF; DGE-1656466 to JDS and OCE-1917058, EAR-1644399 to FJS and JCEI). We thank Dr Olivier Hyvernaud at the French Commissariat à l'Energie Atomique et aux Energies Alternatives, Département Analyse et Surveillance de l'Environnement, for providing seismic data from the Réseau Sismique Polynésien, and for guidance on the removal of their instrument response. Commendation goes to Yann Hello, Sébastien Bonnieux and the team at OSEAN SAS for the design of the third-generation MERMAID instrument, to Alex Burky for help generating Fig. 11, and to Guust Nolet for his support, advice, and encouragement. We thank Ifremer, Genavir, and commander Jean-François Barazer and crew aboard R/V Alis for a string of successful deployments in the South Pacific. We are grateful to the Associate Editor Dr Gabi Laske, Dr Karin Sigloch and an anonymous reviewer for helpful comments that tremendously improved the manuscript. We appreciate Assistant Editor Dr Louise Alexander who deftly guided our manuscript from submission to publication. This publication was supported by the Princeton University Library Open Access Fund.

We are indebted to the many people behind the scenes who collect, organize, store, and disseminate data for use by the community. Next, we do our best to acknowledge each group who helped us collect the data set that we analysed; the Supporting Information contains extra details about how exactly we culled data from each individual contributor.

Waveform data and instrument response metadata corresponding to nearby stations were provided by the following data centres: Institut de Physique du Globe de Paris (IPGP; http://centrededonnee s.ipgp.fr); Incorporated Research Institutions for Seismology Data Management Center (IRIS DMC; http://ds.iris.edu/ds/nodes/dmc/) Raspberry Shake (RASPISHAKE; http://raspberryshake.net/) and the Centre Polynésien de Prévention des Tsunamis in Papetee, Tahiti, French Polynesia. The networks from which we queried nearby data included: GEOSCOPE (G), DOI: 10.18715/GEOSCOPE.G); Australian National Seismograph Network (AU); Red Sismológica Nacional (C1), DOI: 10.7914/SN/C1; Global Seismograph Network-IRIS/IDA (II), DOI: 10.7914/SN/II; Global Seismograph Network_-IRIS/USGS (IU), DOI: 10.7914/SN/IU; Raspberry Shake (AM), DOI: 10.7914/SN/AM; and the Réseau Sismique Polynésien (RSP).

\section{DATA AVAILABILITY AND RESOURCES}

The International Federation of Digital Seismograph Networks (FDSN) has granted Mobile Earthquake Recorder in Marine Areas by Independent Divers (MERMAID) the network code 'MH' (ht tps://fdsn.org/networks/detail/MH/; DOI: 10.7914/SN/MH). MERMAID miniSEED files are at the Incorporated Research Institutions for Seismology Data Management Center (IRIS DMC; $\mathrm{http}: / / \mathrm{ds}$. iris.edu/ds/nodes/dmc/) for public distribution alongside their associated metadata and transfer functions, the latter of which became available (Guust Nolet, Olivier Gerbaud, and Frédéric Rocca, personal communication, 2021) as this manuscript went to press.

The Supporting Information contains text files detailing earthquakes and traveltime residuals computed in the three models discussed here. Continuously updated text files of GPS fixes reported by individual MERMAIDs are available at, for example, ht tp://geoweb.princeton.edu/people/simons/SOM/P0008_all.txt (the stations described here are numbered P0008 through P0025, excluding P0014 and P0015, which never existed) and described at http://geoweb.princeton.edu/people/simons/SOM/hdr.txt. The Supporting Information also includes reviewed and expanded GPS files detailing only the fixes most relevant to this study.

Computer codes developed during this study are publicly available at https://github.com/joelsimon/omnia/ and https://github.com /earthscopeoceans/automaid (Simon et al. 2021a). Excepting those codes written by the authors and the EarthScope-Oceans consortium we used: irisFetch. Events version 2.0.10, available from IRIS, to parse the National Earthquake Information Center Preliminary Determination of Epicenters (NEIC PDE; https:/www.scie ncebase.gov/catalog/item/588b90dae4b0ad6732402989) Bulletin; MatTaup, written in MATLAB by Qin Li in 2002, to estimate theoretical traveltimes in the ak135 model of Kennett et al. (1995); LLNL-Earth3D (https://www-gs.1lnl.gov/nuclear-threat-reduction /nuclear-explosion-monitoring/global-3d-seismic-tomography/) to compute theoretical traveltimes in the LLNL-G3Dv3 model of Simmons et al. (2012); and ObsPy (Beyreuther et al. 2010; https://github.com/obspy/, DOI: 10.5281/zenodo.165135) to convert Raspberry Shake instrument-response metadata from StationXML to SACPZ file formats. All websites referenced in this section were last accessed in June 2021.

\section{REFERENCES}

Abraham, J.P. et al., 2013. A review of global ocean temperature observations: Implications for ocean heat content estimates and climate change, Rev. Geophys., 51(3), 450-483.

Adam, C., Yoshida, M., Suetsugu, D., Fukao, Y. \& Cadio, C., 2014. Geodynamic modeling of the South Pacific superswell, Phys. Earth planet. Inter., 229, 24-39.

Allen, R.V., 1978. Automatic earthquake recognition and timing from single traces, Bull. seism. Soc. Am., 68(5), 1521-1532.

Anthony, R.E., Ringler, A.T., Wilson, D.C. \& Wolin, E., 2019. Do low-cost seismographs perform well enough for your network? An overview of laboratory tests and field observations of the OSOP Raspberry Shake 4D, Seismol. Res. Lett., 90(1), 219-228.

Babcock, J.M., Kirkendall, B.A. \& Orcutt, J.A., 1994. Relationships between ocean bottom noise and the environment, Bull. seism. Soc. Am., 84(6), 1991-2007.

Barnes, C.R., Best, M.M.R., Johnson, F.R., Pautet, L. \& Pirenne, B., 2013. Challenges, benefits, and opportunities in installing and operating cabled ocean observatories: Perspectives from NEPTUNE Canada, IEEE J. Ocean. Eng., 38(1), 144-157.

Barruol, G., 2002. PLUME investigates South Pacific Superswell, EOS, Trans. Am. geophys. Un., 83(45), 511 \& 514.

Beauduin, R., Montagner, J.P. \& Karczewski, J.F., 1996. Time evolution of broadband seismic noise during the French pilot experiment OFM/SISMOBS, Geophys. Res. Lett., 23(21), 2995-2998.

Bent, A.L., Cassidy, J., Prépetit, C., Lamontagne, M. \& Ulysse, S., 2018. Real-time seismic monitoring in Haiti and some applications, Seismol. Res. Lett., 89(2A), 407-415.

Berger, J., Laske, G., Babcock, J. \& Orcutt, J., 2016. An ocean-bottom seismic observatory with near real-time telemetry, Earth Space Sci., 3, $68-77$. 
Beyreuther, M., Barsch, R., Krischer, L., Megies, T., Behr, Y. \& Wassermann, J., 2010. ObsPy: A Python toolbox for seismology, Seismol. Res. Lett., 81(3), 530-533.

Bondár, I. \& Storchak, D., 2011. Improved location procedures at the International Seismological Centre, Geophys. J. Int., 186(3), 1220-1244.

Bradner, H., 1964. Seismic measurements on the ocean bottom, Science, 146(3641), 208-216.

Bradner, H., de Jerphanion, L.G. \& Langlois, R., 1970. Ocean microseism measurements with a neutral buoyancy free-floating midwater seismometer, Bull. seism. Soc. Am., 60(4), 1139-1150.

Burdick, S. \& Lekić, V., 2017. Velocity variations and uncertainty from transdimensional $P$-wave tomography of North America, Geophys. J. Int., 209(2), 1337-1351.

Butler, R. et al., 2000. Hawaii-2 Observatory pioneers opportunities for remote instrumentation in ocean studies, EOS, Trans. Am. geophys. Un., 81(15), 157 \& 162-163.

Calais, E. et al., 2019. Monitoring Haiti's quakes with Raspberry Shake, EOS, Trans. Am. geophys. Un., 100(11), 17-21.

Cohen, A., Daubechies, I. \& Feauveau, J., 1992. Biorthogonal bases of compactly supported wavelets, Comm. Pure Appl. Math., 45(5), 485-560.

Collins, J.A. et al., 2001. Broadband seismology in the oceans: Lessons from the Ocean Seismic Network Pilot Experiment, Geophys. Res. Lett., 28(1), 49-52.

Cottaar, S. \& Lekić, V., 2016. Morphology of seismically slow lower-mantle structures, Geophys. J. Int., 207(2), 1122-1136.

Cottaar, S. \& Romanowicz, B., 2012. An unsually large ULVZ at the base of the mantle near Hawaii, Earth planet. Sci. Lett., 355-356, 213-222.

Cowles, T., Delaney, J., Orcutt, J. \& Weller, R., 2010. The Ocean Observatories Initiative: sustained ocean observing across a range of spatial scales, Mar. Technol. Soc. J., 44(6), 54-64.

Davaille, A., 1999. Simultaneous generation of hotspots and superswells by convection in a heterogeneous planetary mantle, Nature, 402(6763), 756-760.

Davis, R.E., 2005. Intermediate-depth circulation of the Indian and South Pacific oceans measured by autonomous floats, J. Phys. Oceanog., 35(5), 683-707.

Davis, R.E., Webb, D.C., Regier, L.A. \& Dufour, J., 1992. The Autonomous Lagrangian Circulation Explorer (ALACE), J. Atmos. Ocean Tech., 9(3), 264-285.

Davis, R.E., Sherman, J.T. \& Dufour, J., 2001. Profiling ALACEs and other advances in autonomous subsurface floats, J. Atmos. Ocean Tech., 18(6), 982-993.

Dougherty, M.E. \& Stephen, R.A., 1991. Seismo/acoustic propagation through rough seafloors, J. acoust. Soc. Am., 90(5), 2637-2651.

Duennebier, F.K. et al., 1997. Researchers rapidly respond to submarine activity at Loihi volcano, Hawaii, EOS, Trans. Am. geophys. Un., 78(22), 229 \& 232-233.

Duennebier, F.K., Harris, D.W., Jolly, J., Babinec, J., Copson, D. \& Stiffel, K., 2002. The Hawaii-2 Observatory seismic system, IEEE J. Ocean. Eng., 27(2), 212-217.

Ewing, M. \& Vine, A., 1938. Deep-sea measurements without wires or cables, EOS, Trans. Am. geophys. Un., 19(1), 248-251.

Ewing, W.M., Jardetzky, W.S. \& Press, F., 1957. Elastic Waves in Layered Media, Intern. Ser. Earth Sci., McGraw-Hill.

Farra, V., Stutzmann, E., Gualtieri, L., Schimmel, M. \& Ardhuin, F., 2016. Ray-theoretical modeling of secondary microseism $P$ waves, Geophys. $J$. Int., 206(3), 1730-1739.

Favali, P. \& Beranzoli, L., 2006. Seafloor observatory science: a review, Ann. Geophys.-Italy, 49(2-3), 515-567.

Fernando, B., Leng, K. \& Nissen-Meyer, T., 2020. Oceanic high-frequency global seismic wave propagation with realistic bathymetry, Geophys. $J$. Int., 222(2), 1178-1194.

Fox, C.G., Dziak, R.P., Matsumoto, H. \& Schreiner, A.E., 1993. Potential for monitoring low-level seismicity on the Juan de Fuca Ridge using military hydrophone arrays, Mar. Tech. Soc. J., 27(4), 22-30.

French, S.W. \& Romanowicz, B., 2015. Broad plumes rooted at the base of the Earth's mantle beneath major hotspots, Nature, 525(7567), 95-99.
Garnero, E.J., McNamara, A.K. \& Shim, S.-H., 2016. Continent-sized anomalous zones with low seismic velocity at the base of Earth's mantle, Nat. Geosci., 9(7), 481-489.

GEBCO Bathymetric Compilation Group, 2019. The GEBCO_2019 gridA continuous terrain model of the global oceans and land, Tech. rep., British Oceanographic Data Centre, National Oceanography Centre, NERC, UK.

Goldstein, P. \& Snoke, A., 2005. SAC availability for the IRIS community, IRIS DMC Electr. Newslett., 7(1), https://ds.iris.edu/ds/newsletter/vol7/n o1/193/sac-availability-for-the-iris-community/.

Goldstein, P., Dodge, D., Firpo, M. \& Minner, L., 2003. SAC2000: Signal processing and analysis tools for seismologists and engineers, in International Handbook of Earthquake and Engineering Seismology, Part B, Vol. 81 of International Geophysics, pp. 1613-1614, eds Lee, W.H., Kanamori, H., Jennings, P.C. \& Kisslinger, C., Academic Press.

Gould, W.J., 2005. From Swallow floats to Argo-The development of neutrally buoyant floats, Deep-Sea Res. II, 52(3-4), 529-543.

Gualtieri, L., Stutzmann, E., Capdeville, Y., Ardhuin, F., Schimmel, M., Mangeney, A. \& Morelli, A., 2013. Modelling secondary microseismic noise by normal mode summation, Geophys. J. Int., 193(3), 1732-1745.

Gualtieri, L., Stutzmann, E., Juretzek, C., Hadziioannou, C. \& Ardhuin, F., 2019. Global scale analysis and modelling of primary microseisms, Geophys. J. Int., 218(1), 560-572.

Hammond, J.O.S., England, R., Rawlinson, N., Curtis, A., Sigloch, K., Harmon, N. \& Baptie, B., 2019. The future of passive seismic acquisition, Astron. Geoph., 60(2), 2.37-2.42.

Hello, Y. \& Nolet, G., 2020. Floating seismographs (MERMAIDS), in Encyclopedia of Solid Earth Geophysics, pp. 1-6, ed. Gupta, H.K., Encyclopedia of Earth Sciences, doi: 10.1007/978-3-030-10475-7_248-1.

Hello, Y., Ogé, A., Sukhovich, A. \& Nolet, G., 2011. Modern Mermaids: new floats image the deep Earth, EOS, Trans. Am. Geophys. Un., 92(40), 337-338.

Hirata, K. et al., 2002. Real-time geophysical measurements on the deep seafloor using submarine cable in the southern Kurile subduction zone, IEEE J. Ocean. Eng., 27(2), 170-181.

Hosseini, K., Matthews, K.J., Sigloch, K., Shephard, G.E., Domeier, M. \& Tsekhmistrenko, M., 2018. SubMachine: web-based tools for exploring seismic tomography and other models of Earth's deep interior, Geochem. Geophys. Geosys., 19(5), 1464-1483.

Hosseini, K., Sigloch, K., Tsekhmistrenko, M., Zaheri, A., Nissen-Meyer, T. \& Igel, H., 2020. Global mantle structure from multifrequency tomography using $P, P P$ and $P$-diffracted waves, Geophys. J. Int., 220(1), 96-141.

Houser, C., Masters, G., Shearer, P. \& Laske, G., 2008. Shear and compressional velocity models of the mantle from cluster analysis of long-period waveforms, Geophys. J. Int., 174(1), 195-212.

International Seismological Centre, 2015. On-line Bulletin, http://www.isc. ac.uk. doi:10.31905/D808B830.

Joubert, C., Nolet, G., Bonnieux, S., Deschamps, A., Dessa, J.-X. \& Hello, Y., 2016. $P$-delays from floating seismometers (MERMAID), part I: data processing, Seismol. Res. Lett., 87(1), 73-80.

Kagan, Y.Y., 2003. Accuracy of modern global earthquake catalogs, Phys. Earth planet. Inter, 135(2-3), 173-209.

Kebe, H.-W., 1981. Self-noise measurements using a moored sonobuoy with a suspended hydrophone, Mar. Geophys. Res., 5(2), 207-220.

Kelley, D.S., Delaney, J.R. \& the Cabled Array Team, 2016. NSF's cabled array: a wired tectonic plate and overlying ocean, in OCEANS 2016 MTS/IEEE Monterey, 1-10, Proc. IEEE, doi:10.1109/ OCEANS.2016.7761398.

Kennett, B.L.N., Engdahl, E.R. \& Buland, R., 1995. Constraints on seismic velocities in the Earth from traveltimes, Geophys. J. Int., 122(1), 108-124.

Kohler, M.D. et al., 2020. A plan for a long-term, automated, broadband seismic monitoring network on the global seafloor, Seismol. Res. Lett., 91(3), 1343-1355.

Lavender, K.L., Davis, R.E. \& Owens, W.B., 2000. Mid-depth recirculation observed in the interior Labrador and Irminger seas by direct velocity measurements, Nature, 407(6800), 66-69. 
Lewis, B.T.R. \& Dorman, L.M., 1998. Recording teleseisms on the seafloor; an example from the Juan de Fuca plate, Bull. seism. Soc. Am., 88(1), 107116

Lindsey, N.J., Dawe, T.C. \& Ajo-Franklin, J.B., 2019. Illuminating seafloor faults and ocean dynamics with dark fiber distributed acoustic sensing, Science, 366(6469), 1103-1107.

Matabos, M. et al., 2016. Seafloor observatories, in Biological Sampling in the Deep Sea, Chap. 14, pp. 306-337, eds Clark, M., Consalvey, M. \& Rowden, A.A., Wiley, doi:10.1002/9781118332535.ch14.

McCreery, C.S. \& Duennebier, F.K., 1993. Correlation of deep ocean noise $(0.4-30 \mathrm{~Hz})$ with wind, and the Holu Spectrum - a worldwide constant, $J$. acoust. Soc. Am., 93(5), 2639-2648.

McNutt, M.K. \& Fischer, K.M., 1987. The South Pacific superswell, in Seamounts, Islands, and Atolls, Vol. 43 of Geophysical Monograph, pp. 25-34, eds Keating, B.H., Fryer, P., Batiza, R. \& Boehlert, G.W., Amer. Geophys. Union, doi:10.1029/GM043.

McNutt, M.K. \& Judge, A.V., 1990. The Superswell and mantle dynamics beneath the South Pacific, Science, 248(4958), 969-975.

Montagner, J.-P., Lognonné, P., Beauduin, R., Roult, G., Karczewski, J.-F. \& Stutzmann, E., 1998. Towards multiscalar and multiparameter networks for the next century: the French efforts, Phys. Earth planet. Inter., 108(2), $155-174$.

Moulik, P. \& Ekström, G., 2016. The relationships between large-scale variations in shear velocity, density, and compressional velocity in the Earth's mantle, J. geophys. Res., 121(4), 2737-2271.

Munk, W.H., 1974. Sound channel in an exponentially stratified ocean, with application to SOFAR, J. acoust. Soc. Am., 55(2), 220-226.

Nichols, S.M. \& Bradley, D.L., 2016. Global examination of the winddependence of very low frequency underwater ambient noise, $J$. acoust. Soc. Am., 139(3), 1110-1123.

Nolet, G., 2008. A Breviary of Seismic Tomography, Cambridge Univ. Press. Nolet, G. et al., 2019. Imaging the Galápagos mantle plume with an unconventional application of floating seismometers, Sci. Rep., 9, 1326.

Okal, E.A., 2008. The generation of $T$ waves by earthquakes, $A d v$. Geophys., 49, 1-65.

Petitt, R.A. et al., 2002. The Hawaii-2 Observatory, IEEE-OE, 27(2), 245 253.

Pipatprathanporn, S. \& Simons, F.J., 2021. One year of sound recorded by a MERMAID float in the Pacific: Hydroacoustic earthquake signals and infrasonic ambient noise, Geophys. J. Int., doi.org/10.1093/gji/ggab296.

Rawlinson, N., Pozgay, S. \& Fishwick, S., 2010. Seismic tomography: a window into deep Earth, Phys. Earth planet. Inter., 178(3-4), 101-135.

Reid, I., Reichle, M., Brune, J. \& Bradner, H., 1973. Microearthquake studies using sonobuoys: preliminary results from the Gulf of California, Geophys. J. R. astr. Soc., 34(3), 365-379.

Reymond, D., Hyvernaud, O., Talandier, J. \& Okal, E.A., 2003. T-Wave detection of two underwater explosions off Hawaii on 13 April 2000, Bull. seism. Soc. Am., 93(2), 804-816.

Rinard Hinga, B.D., 2015. Ring of Fire: An Encyclopedia of the Pacific Rim's Earthquakes, Tsunamis, And Volcanoes, ABC-CLIO, Santa Barbara, CA.

Roemmich, D. et al., 2009. The Argo Program: Observing the global ocean with profiling floats, Oceanography, 22(2), 34-43.

Romanowicz, B., 2008. Using seismic waves to image Earth's structure, Nature, 451(7176), 266-268.

Romanowicz, B. \& Giardini, D., 2001. The future of permanent seismic networks, Science, 293(5537), 2000-2001.

Romanowicz, B., Stakes, D., Dolenc, D., Neuhauser, D., McGill, P., Urhammer, R. \& Ramirez, T., 2006. The Monterey Bay broadband ocean bottom seismic observatory, Ann. Geophys.-Italy, 49(2-3), 607-623.

Rossby, T. \& Webb, D., 1970. Observing abyssal motions by tracking Swallow floats in the SOFAR channel, Deep-Sea Res., 17(2), 359-365.

Shephard, G.E., Matthews, K.J., Hosseini, K. \& Domeier, M., 2017. On the consistency of seismically imaged lower mantle slabs, Sci. Rep., 7(1), 10976.

Shinohara, M., Kanazawa, T., Yamada, T., Machida, Y., Shinbo, T. \& Sakai, S., 2014. New compact ocean bottom cabled seismometer system deployed in the Japan Sea, Mar. Geophys. Res., 35(3), 231-242.
Simmons, N.A., Forte, A.M., Boschi, L. \& Grand, S.P., 2010. GyPSuM: a joint tomographic model of mantle density and seismic wave speeds, $J$. geophys. Res., 115, B12310.

Simmons, N.A., Myers, S.C., Johannesson, G. \& Matzel, E., 2012. LLNLG3Dv3: global P wave tomography model for improved regional and teleseismic travel time prediction, J. geophys. Res., 117, B10302.

Simon, J.D., Simons, F.J. \& Nolet, G., 2020. Multiscale estimation of event arrival times and their uncertainties in hydroacoustic records from autonomous oceanic floats, Bull. seism. Soc. Am., 110(3), 970-997.

Simon, J.D., Bonnieux, S., Simons, F.J. \& the EarthScope-Oceans Consortium, 2021. automaid, https://github.com/earthscopeoceans/automaid. doi:10.5281/zenodo.5057096.

Simon, J.D., Simons, F.J. \& Irving, J.C.E., 2021. A MERMAID miscellany: Seismoacoustic signals beyond the $P$ wave, Seismol. Res. Lett., 1-11, doi:10.1785/0220210052.

Simons, F.J., Dando, B.D.E. \& Allen, R.M., 2006. Automatic detection and rapid determination of earthquake magnitude by wavelet multiscale analysis of the primary arrival, Earth planet. Sci. Lett., 250(1-2), 214 223 .

Simons, F.J., Nolet, G., Babcock, J.M., Davis, R.E. \& Orcutt, J.A., 2006. A future for drifting seismic networks, EOS Trans. Am. Geophys. Un., 87(31), 305 \& 307.

Simons, F.J., Nolet, G., Georgief, P., Babcock, J.M., Regier, L.A. \& Davis, R.E., 2009. On the potential of recording earthquakes for global seismic tomography by low-cost autonomous instruments in the oceans, $J$. geophys. Res., 114, B05307, doi:10.1029/2008JB006088.

Sladen, A., Rivet, D., Ampuero, J.P., Barros, L.D., Hello, Y., Calbris, G. \& Lamare, P., 2019. Distributed sensing of earthquakes and ocean-solid Earth interactions on seafloor telecom cables, Nat. Commun., 10, 5777.

Stephen, R.A., 1988. A review of finite difference methods for seismoacoustics problems at the seafloor, Rev. Geophys., 26(3), 445-458.

Stephen, R.A., Spiess, F.N., Collins, J.A., Hildebrand, J.A., Orcutt, J.A., Peal, K.R., Vernon, F.L. \& Wooding, F.B., 2003. Ocean Seismic Network Pilot Experiment, Geochem. Geophys. Geosys., 4(10), 1092.

Suetsugu, D. \& Shiobara, H., 2014. Broadband ocean-bottom seismology, Annu. Rev. Earth. planet. Sci., 42, 27-43.

Suetsugu, D. et al., 2005. Probing South Pacific mantle plumes with ocean bottom seismographs, EOS, Trans. Am. geophys. Un., 86(44), 429 \& 435.

Suetsugu, D. et al., 2009. South Pacific mantle plumes imaged by seismic observation on islands and seafloor, Geochem. Geophys. Geosyst., 10(11), Q11014, doi:10.1029/2009GC002533.

Sukhovich, A., Irisson, J.-O., Simons, F.J., Ogé, A., Hello, Y.M., Deschamps, A. \& Nolet, G., 2011. Automatic discrimination of underwater acoustic signals generated by teleseismic $P$-waves: a probabilistic approach, Geophys. Res. Lett., 38(18), L18605, doi:10.1029/2011GL048474.

Sukhovich, A., Irisson, J.-O., Perrot, J. \& Nolet, G., 2014. Automatic recognition of $T$ and teleseismic $P$ waves by statistical analysis of their spectra: An application to continuous records of moored hydrophones, J. Geophys. Res., 119(8), 6469-6485.

Sukhovich, A., Bonnieux, S., Hello, Y., Irisson, J.-O., Simons, F.J. \& Nolet, G., 2015. Seismic monitoring in the oceans by autonomous floats, Nat. Commun., 6, 8027.

Swallow, J.C., 1955. A neutral-buoyancy float for measuring deep currents, Deep-Sea Res., 3(1), 74-81.

Talandier, J., 1993. French Polynesia Tsunami Warning Center (CPPT), Nat. Haz., 7(3), 237-256.

Talandier, J., Hyvernaud, O., Okal, E.A. \& Piserchia, P.-F., 2002. Long-range detection of hydroacoustic signals from large icebergs in the Ross Sea, Antarctica, Earth Planet. Sci. Lett., 203(1), 519-534.

Talandier, J., Hyvernaud, O. \& Maury, R.C., 2016. Unusual seismic activity in 2011 and 2013 at the submarine volcano Rocard, Society hot spot (French Polynesia), Geophys. Res. Lett., 43(9), 4247-4254.

Tanaka, S., Obayashi, M., Suetsugu, D., Shiobara, H., Sugioka, H., Yoshimitsu, J., Kanazawa, T., Fukao, Y. \& Barruol, G., 2009. P-wave tomography of the mantle beneath the South Pacific Superswell revealed by joint ocean floor and islands broadband seismic experiments, Phys. Earth planet. Inter., 172(3-4), 268-277. 
Tanaka, S., Suetsugu, D., Shiobara, H., Sugioka, H., Kanazawa, T., Fukao, Y., Barruol, G. \& Reymond, D., 2009. On the vertical extent of the large low shear velocity province beneath the South Pacific Superswell, Geophys. Res. Lett., 36(7), L07305.

Tesoniero, A., Auer, L. \& Cammarano, L.B.F., 2015. Hydration of marginal basins and compositional variations within the continental lithospheric mantle inferred from a new global model of shear and compressional velocity, J. geophys. Res., 120(11), 7789-7813.

Tolstoy, I. \& Ewing, M., 1950. The T phase of shallow-focus earthquakes, Bull. seism. Soc. Am., 40(1), 25-51.

Tolstoy, M. et al., 2006. A sea-floor spreading event captured by seismometers, Science, 314(5807), 1920-1922.

Toomey, D.R. et al., 2014. The Cascadia Initiative: a sea change in seismological studies of subduction zones, Oceanography, 27(2), 138-150.

Weatherall, P. et al., 2015. A new digital bathymetric model of the world's oceans, Earth Space Sci., 2(8), 331-345.

Webb, S.C., 1998. Broadband seismology and noise under the ocean, Rev. Geophys., 36(1), 105-142.

Webb, S.C. \& Cox, C.S., 1986. Observations and modeling of seafloor microseisms, J. geophys. Res., 91(B7), 7343-7358.

Webb, S.C. \& Crawford, W.C., 2003. Shallow-water broadband OBS seismology, Bull. seism. Soc. Am., 100(4), 1770-1778.

Wessel, P. \& Kroenke, L., 1997. A geometric technique for relocating hotspots and refining absolute plate motions, Nature, 387(6631), 365369.

Wessel, P., Sandwell, D.T. \& Kim, S.-S., 2010. The global seamount census, Oceanography, 23(1), 24-33.

Whitmarsh, R.B., 1970. An ocean bottom pop-up seismic recorder, Mar. Geophys. Res., 1(1), 91-98.

Williams, E.F., Fernández-Ruiz, M.R., Magalhaes, R., Vanthillo, R., Zhan, Z., González-Herráez, M. \& Martins, H.F., 2019. Distributed sensing of microseisms and teleseisms with submarine dark fibers, Nat. Commun., $\mathbf{1 0}, 5778$.

Wright, I.C. et al., 2008. Collapse and reconstruction of Monowai submarine volcano, Kermadec arc, 1998-2004, J. geophys. Res., 113, B08S03.

Zhao, D., Xu, Y., Wiens, D.A., Dorman, L., Hildebrand, J. \& Webb, S., 1997. Depth extent of the Lau back-arc spreading center and its relation to subduction processes, Science, 278(5336), 254-257.

\section{SUPPORTING INFORMATION}

Supplementary data are available at $G J I$ online.

Figure S1: MERMAID seismogram after automatic preliminary matching. The blue trace in the top panel is the raw seismogram, while the grey traces below are wavelet-subspace projections at five scales, each overlain by their associated Akaike information criterion (AIC) curve (black) and AIC-based arrival-time pick (purple). The top panel is annotated with the theoretical arrival times of various phases from five distinct earthquakes, as noted in the subscripts, computed in the ak135 velocity model, and marked in time by vertical lines. These represent all the phases which have theoretical arrival times within the time window of the seismogram, associated with known global seismic events in the catalogues queried from IRIS. The time of the first-arriving phase associated with the largest earthquake in the set $\left(p_{1}\right)$ is marked by a solid red vertical line. Its theoretical arrival time agrees well with the AIC-based arrival-time picks (which are independent of seismology) at the first three scales. The agreement of these two distinct arrival-time estimation methods lends itself to the confident assignment of this seismogram to the 'identified' category. During manual review this figure (and a secondary, zoomed in version) is displayed to the researcher, along with the event metadata associated with all potentially matching events, and the researcher is led through a series of intuitive prompts in MATLAB for easy matching and sorting.
Figure S2: Fig. 10 of the main text, remade considering only the subset of events for which data existed for at least one station within each instrument class.

Figure S3: The 12 highest-SNR signals recorded by traditional island stations considering the catalogue of events common to all three instrument classes. They are presented in the same format as Fig. 9 of the main text, except that the residuals are in reference to the standard ak135 model (eq. A1 of the main text). The seismograms are plotted in units of velocity $\left(\mathrm{nm} \mathrm{s}^{-1}\right)$, and the signals are coloured green.

Figure S4: The 12 highest-SNR signals recorded by MERMAID considering the catalogue of events common to all three instrument classes, presented in the same format as Fig. 9 of the main text.

Figure S5: The 12 highest-SNR signals recorded by Raspberry Shake island stations considering the catalogue of events common to all three instrument classes. They are presented in the same format as Fig. 9 of the main text, except that the residuals are in reference to the standard ak135 model (eq. A1 of the main text). The seismograms are plotted in units of velocity $\left(\mathrm{nm} \mathrm{s}^{-1}\right)$, and the signals are coloured raspberry.

Figure S6: Unfiltered seismograms from RSP.PAE (purple), RSP.PMOR (red), G.PPTF (grey) of a nearby great earthquake. The SACPZ files corresponding to the two RSP stations were written by the authors, and that corresponding to G.PPTF was provided by IRIS. The similarity of the waveforms, both in phase and amplitude, proves that our SACPZ files are correct.

Please note: Oxford University Press is not responsible for the content or functionality of any supporting materials supplied by the authors. Any queries (other than missing material) should be directed to the corresponding author for the paper.

\section{A P PENDIX}

\section{A1 ESTIMATING DELAY TIMES AND UNCERTAINTIES}

\section{A1.1 The arrival-time pick}

We use the Akaike information criterion (AIC) based arrival-time picking scheme of Simon et al. (2020). In practice, the procedure maximizes the likelihood that a time-pick partitions the seismogram into a noise and a signal segment by identifying the maximum SNR considering the set of all possible 'changepoints'. We use Monte Carlo resimulation and repicking for uncertainty estimation (Method 1 of Simon et al. 2020). Unlike Simon et al. (2020) we do not iterate over wavelet-scale sub-bands.

We use the same picking procedure for MERMAID, traditional seismometers, and Raspberry Shakes. First, a 60 s segment of the demeaned and detrended seismogram, centred on the theoretical phase arrival time, is multiplied by a symmetric Tukey window, flat in its $30 \mathrm{~s}$ interior and with a $15 \mathrm{~s}$ cosine taper at either end. Next, the tapered seismogram is band-pass filtered between 1 and $5 \mathrm{~Hz}$ using a one-pass, four-pole Butterworth filter. Finally, the picking scheme is run within the central $30 \mathrm{~s}$ segment. Fig. 9 shows nine examples of complete segments considered for our AIC picks.

\section{A1.2 The traveltime residual}

Our traveltime residual is the time difference between our time pick, $t_{\mathrm{AIC}}$, and the theoretical traveltime of the corresponding phase computed in the model of interest. 'Traveltimes' and 'arrival times' tag 
the same absolute time, in different reference frames. The 'traveltime' is the time elapsed between the event origin time and the theoretical or observed phase arrival. The 'arrival time' is the time elapsed between the start of the seismogram and the phase arrival.

For all records of traditional sensors and Raspberry Shake stations on nearby islands the traveltime residual is simply

$t_{\mathrm{res}}=t_{\mathrm{AIC}}-t_{\mathrm{ak} 135}$,

where the relevant model is the 1-D ak135. Computing MERMAID traveltime residuals requires adjusting for bathymetry and MERMAID cruising depth,

$t_{\text {res }}^{\star}=t_{\mathrm{AIC}}-t_{\mathrm{ak} 135}^{\star}$,

as explained in Section A1.3.

We also recompute residuals for MERMAID using the fully 3-D, elliptical LLNL-3DGv3 crust and mantle model of Simmons et al. (2012), defining

$t_{\mathrm{res}}^{\oplus}=t_{\mathrm{AIC}}-t_{\mathrm{LLNL}}$.

\section{A1.3 Adjusting for bathymetry and MERMAID cruising depth}

Eq. (A2) required adjusting the ak135 traveltime for bathymetry, the water layer, and a submerged receiver. There, $t_{\mathrm{ak} 135}^{\star}$ is the theoretical traveltime computed in the adjusted ak135 velocity model,

$t_{\mathrm{ak} 135}^{\star}=t_{\mathrm{ak} 135}+t_{\mathrm{adj}}$,

where $t_{\text {adj }}$ is the difference between the traveltimes in the adjusted and standard models. Because we assume that the theoretical ray paths are identical in both models until reaching the seafloor, $t_{\text {adj }}$ equals the difference between the traveltime of the converted phase from the seafloor to MERMAID and the traveltime of the direct phase through a rock layer equal in thickness to the local water depth,

$t_{\mathrm{adj}}=\frac{z_{\mathrm{W}}-z_{\mathrm{MER}}}{v_{\mathrm{w}} \cos \theta_{\mathrm{w}}}-\frac{z_{\mathrm{W}}}{v_{\mathrm{r}} \cos \theta_{\mathrm{r}}}$.

In this convention $z$ is depth in mositive below the surface, $v$ is the acoustic velocity in $\mathrm{m} \mathrm{s}^{-1}, \theta$ is the angle of incidence in degrees, and subscripts ' $w$ ' and ' $r$ ' denote those values in water and rock, respectively. Bathymetry at the recording location $\left(z_{\mathrm{w}}\right)$ is interpolated using the 2014 General Bathymetric Chart of the Oceans (GEBCO) Bathymetric Compilation Group model (Weatherall et al. 2015), and MERMAID depth at the time of trigger $\left(z_{\mathrm{MER}}\right)$ is measured via its onboard pressure sensor. The standard dive depth is $1500 \mathrm{~m}$. We assume an acoustic velocity of $1500 \mathrm{~m} \mathrm{~s}^{-1}$ for water and $5800 \mathrm{~m} \mathrm{~s}^{-1}$ for rock, as with the upper layer in ak135. The incidence angle of the water column conversion is given by Snel's law (Nolet 2008),

$\theta_{\mathrm{w}}=\arcsin \left(\frac{v_{\mathrm{w}} \sin \theta_{\mathrm{r}}}{v_{\mathrm{r}}}\right)$

Eq. (A5) yields an adjustment $t_{\mathrm{adj}}=+0.98 \mathrm{~s}$ for a $P$ wave incident at $0^{\circ}$ on the seafloor of a $4000 \mathrm{~m}$ deep ocean, and recorded by MERMAID at a cruising depth of $1500 \mathrm{~m}$ - in other words, for an 'average' ocean depth and an 'average' MERMAID cruising depth.

Teleseismic waveforms bottoming in the lower mantle are incident at small angles on the seafloor. A rule of thumb holds that $1 \mathrm{~s}$ should be added to traveltimes computed in the ak135 velocity model (or, equivalently, $1 \mathrm{~s}$ should be removed from MERMAID traveltime residuals computed against ak135 as in eq. A1). The residuals reported by Simon et al. (2020) for the second-generation
MERMAID data were not corrected for bathymetry or cruising depth and hence this rule should be applied to the residuals reported there.

Also note that while we have spoken generally in this section about 'the' adjusted model, the specific time adjustment applied in eq. (A4) is dependent on source-station geometry (via the incidence angle), ocean depth, and MERMAID cruising depth, and thus differs for every seismogram. The Supporting Information details these 1-D traveltime adjustments, as well as the analogous 3-D adjustments to convert between ak135 and LLNL-3DGv3, which are also specific to individual seismograms.

\section{A1.4 The uncertainty on the residual}

Our AIC-based picking procedure provides uncertainty estimates. Method 1 of Simon et al. (2020), used here, leverages the statistics of the seismogram to construct synthetic sequences from which timing-error distributions are generated via Monte Carlo resimulation. Every assessed seismogram is simply modelled as a noise segment preceding a signal segment, individually generated by an uncorrelated Gaussian distribution, concatenated at the presumed arrival time. The means and variances of the two segments are estimated from the data themselves. In practice, zero-mean noise and zero-mean signal sequences result in synthetics whose two segments differ only in variance, and which match the SNR and the picked changepoint of the seismogram after which they are modelled. A new AIC arrival time is picked on each synthetic, and the signed distance between it and the AIC pick on the real seismogram (the assumed truth) is tallied over 1000 simulations to generate the error distribution. We use twice the standard deviation of this distribution, $2 \mathrm{SD}_{\text {err }}$, as our measure of timing uncertainty, in seconds.

See Data Availability and Resources and the Supporting Information for links to computer codes to compute the variables discussed in this section.

\section{A2 NEARBY ISLAND SEISMIC STATIONS}

\section{A2.1 Data retrieval}

We queried IRIS for terrestrial seismometers with public data after July 2018. The search returned 19 stations: 14 'traditional' seismic sensors from GEOSCOPE (G), the Australian National Seismograph Network (AU), the Red Sismológica Nacional (C1) and the Global Seismograph Networks IRIS/IDA (II) and IRIS/USGS (IU); and five low-cost Raspberry Shake (Bent et al. 2018; Anthony et al. 2019; Calais et al. 2019) instruments (AM). Table A1 lists these stations and their locations. They amount to one for every 2.3 million $\mathrm{km}^{2}$, an area larger than Saudi Arabia, and they are very inhomogeneously clustered on islands. Additionally we obtained data from six short-period seismometers in the Réseau Sismique Polynésien (RSP) maintained by the Centre Polynésien de Prévention des Tsunamis (CPPT), in Papeete, Tahiti, French Polynesia (Talandier 1993). Stations codes and locations are listed in Table A2. Data from RSP have been used to seismically investigate underwater explosions (Reymond et al. 2003), Antarctic ice-calving events (Talandier et al. 2002), and submarine volcanism (Wright et al. 2008; Talandier et al. 2016). Fig. 4(a) shows the locations of the nearby stations in Tables A1 and A2 relative to the SPPIM array.

We retrieved every available seismic trace from these stations corresponding to all 288 identified events in our MERMAID catalogue beginning $5 \mathrm{~min}$ before the first arrival predicted by ak135. 
Table A1. Nearby stations with data available from Incorporated Research Institutions for Seismology (IRIS).

\begin{tabular}{lcrr}
\hline FDSN code & Station & Latitude & Longitude \\
\hline G & FUTU & -14.3076 & -178.1210 \\
G & PPTF & -17.5896 & -149.5652 \\
G & TAOE & -8.8549 & -140.1477 \\
AU & NIUE & -19.0763 & -169.9272 \\
C1 & VA02 & -27.1602 & -109.4345 \\
II & MSVF & -17.7448 & 178.0527 \\
II & RPN & -27.1266 & -109.3343 \\
IU & AFI & -13.9093 & -171.7772 \\
IU & FUNA & -8.5259 & 179.1965 \\
IU & KNTN & -2.7744 & -171.7185 \\
IU & PTCN & -25.0713 & -130.0953 \\
IU & RAO & -29.2450 & -177.9290 \\
IU & RAR & -21.2125 & -159.7733 \\
IU & XMAS & 2.0448 & -157.4456 \\
AM & R028A & -17.6936 & -149.5746 \\
AM & R06CD & -17.5675 & -149.5706 \\
AM & R0EF4 & -17.7207 & -149.2979 \\
AM & *RC78F & -17.5315 & -149.4748 \\
& & -17.3423 & -145.5090 \\
AM & RF737 & -17.5315 & -149.4746 \\
\hline
\end{tabular}

* Station moved during study period.

Table A2. Nearby stations from the Réseau Sismique Polynésien (RSP).

\begin{tabular}{lccc}
\hline Network & Station & Latitude & Longitude \\
\hline RSP & PAE & -17.6610 & -149.5797 \\
RSP & TVO & -17.7825 & -149.2516 \\
RSP & PMOR & -15.0022 & -147.8941 \\
RSP & VAH & -15.2365 & -147.6284 \\
RSP & TBI & -23.3488 & -149.4608 \\
RSP & RKT & -23.1247 & -134.9720 \\
\hline
\end{tabular}

For each station in Table A1 we requested traces for all $\mathrm{M}^{*}$ (mid period; sampling rate between 1 and $10 \mathrm{~Hz}$ ), B* (broad band; 10-80 Hz), $\mathrm{H}^{*}$ (high broad band; $80-250 \mathrm{~Hz}$ ), S* (short period; 10-80 Hz), and $\mathrm{E}^{*}$ (extremely short period; 10-80 Hz) vertical channels. No data from mid-period instruments were returned, and all Raspberry Shake stations were short-period or extremely shortperiod. This yielded 7424 traces. Of those, 6992 were from traditional sensors, with data recorded during all 288 earthquakes in the MERMAID catalogue, and 432 from Raspberry Shake instruments, accounting for data recorded during a subset of only 168 of those same earthquakes. Unlike the traditional stations that were in place before MERMAID P0008 was deployed, not all Raspberry Shake stations in Table A1 were installed before the SPPIM deployment.

From the short-period instruments at the stations in Table A2 we obtained 1534 traces, corresponding to 284 MERMAID events. These data are not publicly distributed or long-term archived.

\section{A2.2 Data processing and traveltime picking}

Each trace had its mean and trend removed, and was tapered at both ends with a symmetric cosine taper of 5 per cent the length of the trace (the SAC defaults). The instrument responses available in pole-zero (SACPZ) files were removed by deconvolution using SAC (Goldstein et al. 2003; Goldstein \& Snoke 2005), converting the raw data from digital counts into velocity seismograms. Each trace was high-pass filtered above $0.1 \mathrm{~Hz}$ and low-passed below $10 \mathrm{~Hz}$. These frequencies were chosen to correspond as closely as possible to the sensitivity band of a MERMAID instrument, whose pressure records are filtered between those bounds before digitization, and whose instrument gain is flat (and negative!) within that bandwidth (see Section A.3 and the Supporting Information).

SACPZ and StationXML files with response data were readily available for the stations in Table A1. SACPZ files were not available for the stations in Table A2. The Supporting Information contains the necessary details and software to perform instrument correction, which will be of use to others.

Finally, note that Fig. 5 serves merely as a visual aid to appreciate the types of signals that MERMAID records compared with other stations, given the same earthquake. We do not use the grey waveforms as shown there to make first-arrival picks. Rather, for every first-arrival time reported in this study, regardless of instrument, we make the arrival-time picks on segments like those in Fig. 9 (and Figs S3-S5), not like those shown in Fig. 5. Hence, regardless of instrument type, each trace was processed as described in Section A1. For the island-station data, the only difference was that, if required, they were decimated to 20 or $25 \mathrm{~Hz}$ to match the sampling frequency of MERMAID, and no bathymetric (or elevation) time corrections were applied. Seismograms were rejected if they were less than $200 \mathrm{~s}$ long, if they had any missing data within the taper window described in Section A1.1, or if the theoretical first-arrival time was near enough to an edge to result in the deconvolution taper used to remove the instrument response overlapping with the taper used for arrival-time picking.

\section{A3 MERMAID POLES AND ZEROS}

Finally, we print the poles and zeros for the third-generation MERMAID, as experimentally derived by Guust Nolet, Olivier Gerbaud and Frédéric Rocca. A report written by those authors entitled, 'Determination of poles and zeroes for the MERMAID response', which details the experimental setup and results, is additionally included as Supporting Information to this study. Note the negative constant.

$$
\begin{aligned}
& \text { * INPUT UNIT : } \mathrm{Pa} \\
& \text { * OUTPUT UNIT : COUNTS } \\
& \text { POLES } 7 \\
& 0.50151 \mathrm{E}-01 \quad 0.50405 \mathrm{E}-01 \\
& 0.50151 \mathrm{E}-01 \quad-0.50405 \mathrm{E}-01 \\
& 0.49249 \mathrm{E}-01 \quad 0.59334 \mathrm{E}-03 \\
& 0.49249 \mathrm{E}-01-0.59334 \mathrm{E}-03 \\
& -0.72882 \quad 0 \text {. } \\
& -0.58397 \mathrm{E}-01 \quad 0.85986 \mathrm{E}-04 \\
& -0.58397 \mathrm{E}-01 \quad-0.85986 \mathrm{E}-04 \\
& \begin{array}{lr}
\text { ZEROS } & \multicolumn{1}{c}{7} \\
0.49813 \mathrm{E}-01 & 0.48929 \mathrm{E}-01 \\
0.49813 \mathrm{E}-01 & -0.48929 \mathrm{E}-01 \\
0.55271 \mathrm{E}-01 & 0.45316 \mathrm{E}-01 \\
0.55271 \mathrm{E}-01 & -0.45316 \mathrm{E}-01 \\
-0.23688 \mathrm{E}-01 & 0.38878 \mathrm{E}-01 \\
-0.23688 \mathrm{E}-01 & -0.38878 \mathrm{E}-01 \\
0 . & 0 .
\end{array}
\end{aligned}
$$

CONSTANT $\quad-0.14940 \mathrm{E}+06$ 